University of San Diego

Digital USD

1994

\title{
Factors Associated with Women's Decisions to Obtain Routine Cervical Cancer Screening in a Prepaid Health Care System
}

Vicki DeBaca DNSc

University of San Diego

Follow this and additional works at: https://digital.sandiego.edu/dissertations

Part of the Nursing Commons

\section{Digital USD Citation}

DeBaca, Vicki DNSc, "Factors Associated with Women's Decisions to Obtain Routine Cervical Cancer Screening in a Prepaid Health Care System" (1994). Dissertations. 243.

https://digital.sandiego.edu/dissertations/243

This Dissertation: Open Access is brought to you for free and open access by the Theses and Dissertations at Digital USD. It has been accepted for inclusion in Dissertations by an authorized administrator of Digital USD. For more information, please contact digital@sandiego.edu. 
FACTORS ASSOCIATED WITH WOMEN'S DECISIONS TO OBTAIN ROUTINE CERVICAL CANCER SCREENING IN A PREPAID HEALTH CARE SYSTEM

By

Vicki DeBaca

\begin{abstract}
A dissertation presented to the FACULTY OF THE PHILIP Y. HAHN SCHOOL OF NURSING UNIVERSITY OF SAN DIEGO
\end{abstract}

In partial fulfillment of the requirement for the degree DOCTOR OF NURSING SCIENCE

Summer 1994 


\section{ABSTRACT}

The focus of this research study was to explore the factors affecting women's decisions to participate in preventive cervical cancer screening using a conceptual model proposed by Cummings, Becker, and Maile (1980). This descriptive-comparative study investigated the effect between the components of this model (age, education level, race, general barriers, psychological barriers, evaluation of health care, threat of illness, knowledge, social network) and the outcome variable of intent to participate in cervical cancer screening examinations. This study also examined whether there were differences in the predictor variables between two groups of women: those that have had a recent Pap examination and those that have not.

The research questions were answered with aita obtained from two groups of women members of a southern California Health Maintenance Organization (HMO) and analyzed using multiple regression and t-tests. In the group of women with no recent history of Pap examination, evaluation of health care and race accounted for $17 \%$ of the explained variance. For the group of women who had recently participated in cervical cancer screening, evaluation of health care and psychological barriers accounted for $29 \%$ of the variance in future health screening intention. No significant differences in the variables were found between the two groups of women.

\section{iii}


Copyright by Vicki DeBaca 1994

All Rights Reserved

iv

Reproduced with permission of the copyright owner. Further reproduction prohibited without permission. 


\section{ACKNOWLEDGEMENTS}

I would like to express my sincere appreciation to those who helped make this dissertation possible. I am indebted to my family for their tolerance, support, and encouragement: my husband, Frank who helped both technically and emotionally; my parents who helped with the children and kept the household running; and to my girls, Jessica, Sarah, and Allison for being such delightful children.

I also extend a special thanks to my dissertation committee: Dr. Rita Halpern, chair; Dr. Jan Harrison; and Dr. Karen Sechrist for their support, advice, and guidance that helped me to successfully complete this dissertation. 
TABLE OF CONTENTS

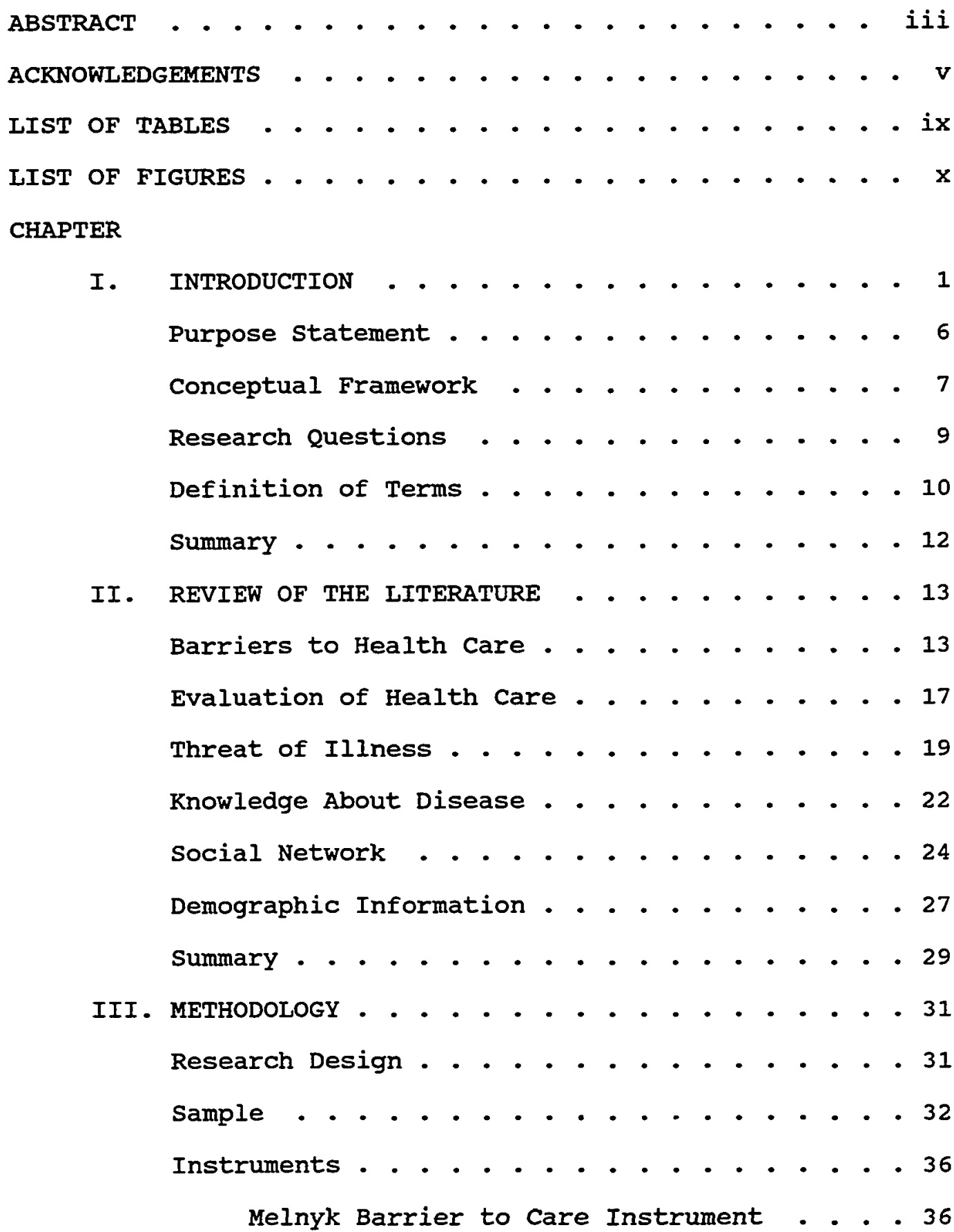

vi 
DeBaca Psychologic Barriers to Care

Instrument ............... 38

Health Measures Scale ........ . 40

Champion Health Belief Model Scale. . . 42

Factual knowledge Questionnaire . . . . 44

Interpersonal Support of Health Habit

Change Scale... . . . . . . . . 45

Demographic Questionnaire . . . . . 46

Intent to Participate in Pap Screening . 47

Data Collection Procedures . . . . . . 47

Data Analysis Plan . . . . . . . . . 48

Summary . . . . . . . . . . . . . 51

IV. RESULTS . . . . . . . . . . . . . . . 52

Data Reduction . . . . . . . . . . 52

Data Analysis Related to Research Questions . . 53

Residual Analysis . . . . . . . . . . 58

Summary . . . • . • . . . . . . . . 59

V. SUMMARY, DISCUSSION AND RECOMMENDATIONS . . . . 61

Implications and Recommendations . . . 69

Nursing Research . . . . . . . . . 69

Nursing Practice \& Administration . . . 72

Nursing Education .. . . . . . . 73

Summary . . . . . . . . . . . . . . 73

REFERENCES • • • • • . . . . . . . . . . . 75

APPENDICES . . . . . . . . . . . . . . . 88

A. Melnyk Barriers to Care Instrument . . . 89

vii 
B. DeBaca Psychological Barriers to Care

Instrument ............. . 92

C. Benefits Subscale of the Health

Measures Scale . . . . . . . . . 94

D. Susceptibility and Seriousness subscales of the Champion Health Belief Model

Scale. . . . . . . . . . . . 96

E. Factual Knowledge Questionnaire . . . . 98

F. Interpersonal Support of Health Habit

Change Instrument . . . . . . . . 100

G. Demographic Questionnaire . . . . . 102

H. Expedited Review Forms: The Protection of

Human Subjects .......... 105

viii

Reproduced with permission of the copyright owner. Further reproduction prohibited without permission. 


\section{LIST OF TABLES}

Table

Page

1. Demographic Profile of the Sample . . . . . . 35

2. Instrumentation summary . . . . . . . . . . 37

3. Bivariate correlations for study scales . . . . . 54

4. Multiple Regression Between the Predictor Variables and Women's Intent to Participate in Pap . . . . . . . . . . . . . . . 56

5. Comparison of Two Groups of Women in Relation to the Study Variables . . . . . . . . . . . . . 60 


\section{List of Figures}

Figure

Page

1. Conceptual Model of Factors Affecting Pap Smear Decisio:s Making 
CHAPTER I

INTRODUCTION

The prevalence of cancer is widespread and is second only to heart disease as the leading cause of death in the United States. In 1989, cancer accounted for one of every five deaths. Alarmingly, cancer rates for women continue to rise with the leading causes of death in women attributed to breast cancer, colorectal cancer, lung cancer, and uterine (including cervical) cancer (American Cancer Society, 1992).

It has been estimated that a 25 to $50 \%$ cancer mortality reduction could be obtained by the application of current knowledge in the early detection and treatment of cancer (National Cancer Institute, 1986). Decreased mortality rates for cancer have been attributed to early detection and treatment. Screening mammography, cervical smear tests, and fecal occult blood testing have all helped to reduce cancer deaths (International Agency for Research on Cancer Working Group on Evaluation of Cervical Screening Programs, 1986; National Cancer Institute, 1986). However, despite all that is known about the early detection of cancer, findings from the National Health Interview Survey have indicated that large numbers of women who would benefit from screening are not participating in screening programs (National Cancer 
Institute, 1986). The National Health Interview Study found that only $79 \%$ of women had Pap smears at the recommended screening intervals (Hayward, 1988).

since cancer statistics are generally reported by the cause of death, the significance and impact of cervical cancer is generally overlooked. Cancer of the cervix is not usually associated with death until the cancer spreads beyond the cervical site to involve other organs. This method of reporting death statistics serves to undermine the significance of cervical cancer as a leading health risk. Cancer of the cervix is the most frequent site of cancer in women, far exceeding the occurrence of other cancers (USDHHS, 1990).

One of the most widely recognized and widely available programs for screening and detection of cervical cancer is the Papanicolaou (Pap) smear. The Pap smear has been demonstrated to be a reliable method to identify early cases of cervical cancer. The use of Pap smears for early detection of cervical cancer has reduced the death rate by 73\% since 1950 (American Cancer Society, 1992; USDHHS, 1990). While the death rate from cervical cancer has fallen during the past four decades, survival rates have not improved since the $1970^{\prime} \mathrm{s}$. This is largely attributed to an increase in the diagnosis of cervical cancer at later stages. Large numbers of women, particularly the elderly and lower socioeconomic groups are not adequately screened 
(Blesch \& Prohaska, 1991; Hayward, 1988; USDHHS, 1990). In fact, the Rand Health Insurance Project showed that of women ages 17 to 44 only $66 \%$ received a Pap exam within the previous three years, and only 57\% of women ages 45 to 65 received the examination in the previous three years. Identification of the factors associated with participation in health screening can have a significant impact on improving the morbidity and mortality associated with cervical cancer.

The United States Government, through the Public Health Service, has recently completed a national activity for setting health priorities for the nation. The result of this activity is published in Healthy People 2000: National Health Promotion and Disease Prevention Objectives (USDHHS, 1990). This comprehensive document focuses on the health issues of most concern to the American public, and identifies health improvement goals and specific objectives designed to meet these goals.

Participation or non-participation in preventive health screening ultimately effects the ability of our nation to achieve its health goals by the year 2000. The national health goal for cervical cancer is to reduce the 1987 death rate of 2.8 per $1,000,000$ to 1.3 per $1,000,000$ women (USDHHS, 1990). The specific goal calls for a $7 \%$ increase in the number of women screened for cervical cancer (USDHHS, 1990). 
Research findings from studies such as this can expand nursing knowledge about factors influencing women's health behavior and assist in the identification of interventions that will increase consumer participation in preventive health screening. Identification of consumer perceived barriers to preventive screening for early cervical cancer provides information that allows for the reduction or elimination of barriers. The ultimate goals are improvement in the utilization of preventive screening services and reduction of morbidity and mortality associated with cervical cancer.

Lack of utilization of preventive health and screening services such as Pap smears has been the focus of numerous studies. Results of such studies have been mixed, with no single factor emerging as the most significant variable in predicting utilization of prevention services. Factors preceding an individual's use of preventive or screening services generally fall into three major categories: economic, structural, and behavioral barriers (Warnecke, Havlieck, \& Manfredi, 1983). Economic factors limiting use of health care services are those related to lack of health insurance coverage or limited financial resources to cover the cost of health care. Individuals in lower socioeconomic groups are less likely to be able to afford health care or insurance coverage and, therefore, do not utilize preventive health screening (Bice, Eichorn, \& Fox, 1972; Dutton, 1978). 
Structural factors that impede the utilization of preventive health care are those that relate to the lack of a health care provider to either perform an examination such as a colorectal screening or pap smear, or provide education and encouragement as in the case of breast self exam (Christopherson, Lundin, Mendez, \& Parker, 1976; Lundin, Christopherson, Mendez, \& Parker, 1963).

Finally, behavioral models attempt to explain the individual's motivation to act to preserve health by seeking out health services. Reasons why women participate in screening are complex. Therefore, only a small proportion of the variation in utilization of screening services has been explained by behavioral studies. Additionally, variables associated with utilization of one type of preventive health service do not always predict an individual's utilization of other types of service (Gillam, 1991).

Since the participation in screening programs such as Pap smears is a voluntary action controlled by the individual, it is of interest to determine what the individual perceives as barriers to participation in such programs. Research has indicated that women may not participate in cervical screening due to factors inherent in the system such as lack of access to health care providers, lack of insurance or other means to pay for health services, or lack of a primary care provider (Aday, 1975; Dutton, 
1978). If these were, in fact, the only barriers, then systems that control for these barriers such as HMOs or programs that provide free screening should have a higher attendance rate for screening. Analysis of information received from the National Health Interview Survey (Harlan, Bernstein, \& Kessler, 1991) revealed no significant differences in the rate of utilization depending on the source of care. Members of HMOs and patients of private physicians had similar Pap screening rates. Only women who had no usual source of care had lower utilization rates. Similar results have been reported by Peters, Bear, and Thomas (1989) who found that while women with regular providers had higher examination rates there was no difference in screening rates between patients of physicians who practiced alone and HMO members. Apparently other unexplained and unmeasured barriers exist that prevent utilization of health screening services.

\section{Purpose}

Research is needed to identify, from the consumer perspective, the factors associated with seeking or not seeking preventive health screening. Since a large part of the utilization of services rests with the consumer's behavior, identification of factors that have an impact on consumers' participation in health screening activities is important in improving access to health promotion services. The purpose of this study was to investigate the effect 
of the threat of illness, evaluation of health care, knowledge about disease, social network, accessibility of health services and selected demographic variables on the actual participation or non-participation of women in preventive screening for cervical cancer.

\section{conceptual Framework}

The conceptual framework for this study was derived from a composite model of variables explaining health action proposed by Cummings, Becker, and Maile (1980) (see Figure 1). This framework was derived from 109 variables related to health action from 14 behavioral models (Andersen, 1968; Andersen \& Bartkus, 1973; Antonovsky and Kats, 1970; Fabrega, 1973; Green, 1975; Hochbaum, 1958; Kar, 1977; Kasl and Cobb, 1966; Kosa and Robertson, 1975; Langlie, 1977; Mechanic, 1968; and Rosenstock, 1966). The original authors of each of the respective models were asked to categorize the variables into groups of similarity. Using smallest space anaiysis, six dimensions predictive of health actions among all of the models emerged. These summary categories were: threat of illness, evaluation of health care, knowledge about disease, social network, accessibility of health services, and selected demographic variables. Becker (1990), concluded that the variables identified in each of the 14 different models had much similarity and that identification and combination of the variables 


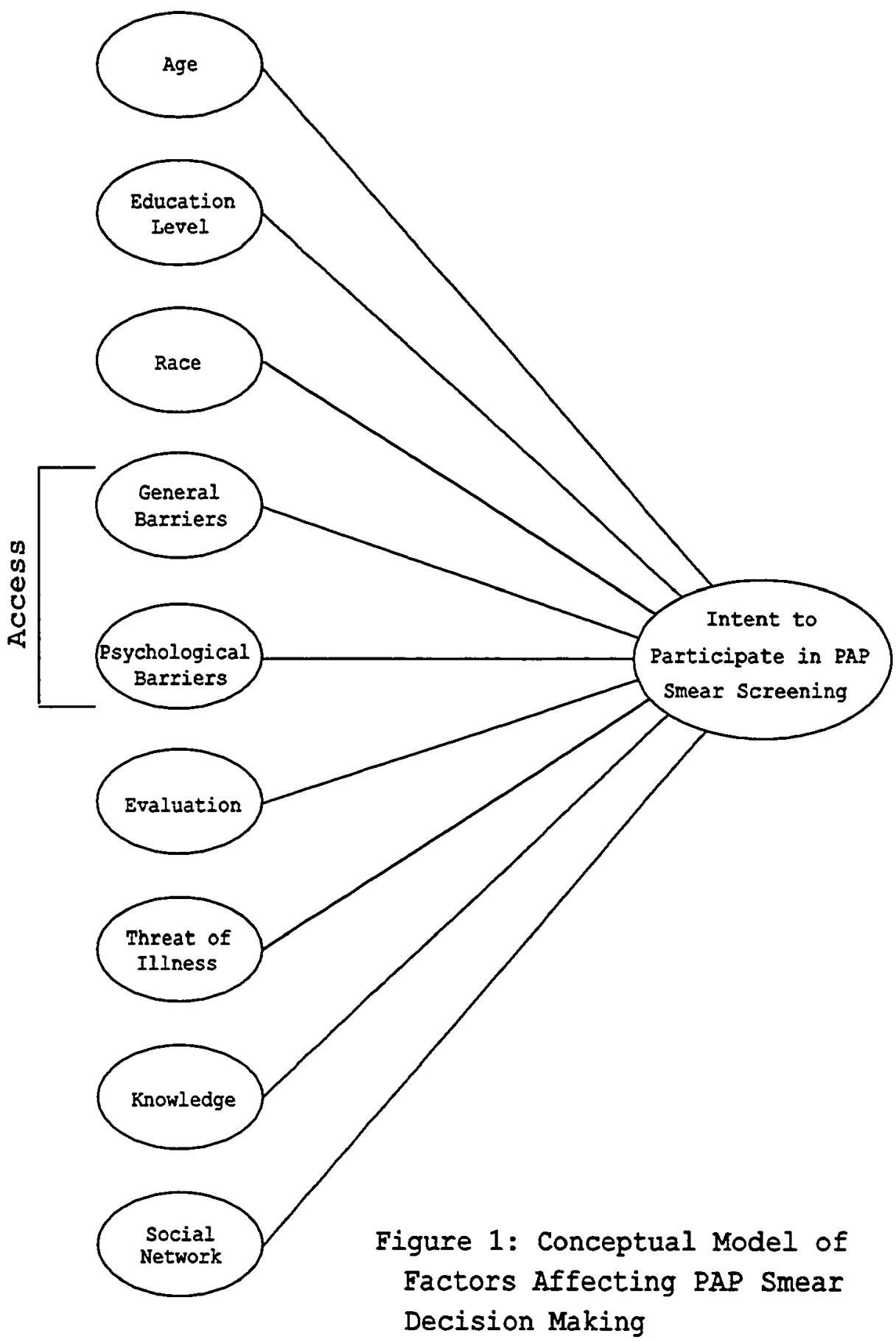


provided a more useful framework that could be used to test the influence of the variables on health behaviors.

Using this composite model as the framework, this study seeks to identify the effect of the predictor variables of age, education level, race, barriers, evaluation of health care, threat of illness, knowledge, social network on the dependent variable of intent to participate in health screening.

\section{Research Questions}

This study addressed the following research questions:

1. What is the effect of age, education level, race, perceived general barriers, perceived psychological barriers, evaluation of health care, threat of illness, knowledge, and social network on the future intention to participate in preventive health screening for cervical cancer for women who have recently participated in preventive cervical screening?

2. What is the effect of age, education level, race, perceived general barriers, perceived psychological barriers, evaluation of health care, threat of illness, knowledge, and social network on the future intention to participate in preventive health screening for cervical cancer for women who have not recently participated in preventive cervical cancer screening?

3. What significant predictor differences exist between the group of women who participate in preventive 
cervical cancer screening and the group of women who do not participate in preventive cervical cancer screening?

Definition of Terms

The nine major variables used in this study are defined as follows:

Demographic Information. A demographic questionnaire was used to obtain data on age, sex, race, religion, and education.

Perceived general barriers to health care services. Accessibility refers to the individual's ability to participate in health services. Frequently, enrollment in a health insurance plan or ability to pay the cost of services defines accessibility. In this study, this type of barrier was controlled by the setting. The focus of accessibility was on the other general barriers that may prevent a consumer from accessing services. General barriers were operationalized in this study by the Melnyk (1990) Barriers to Care scale which consists of five dimensions: fear, cost, interpersonal relationships, inconvenience, and location.

Perceived psychological barriers to health services. Additional internal barriers that may prevent access to services were operationalized by the DeBaca (1993) Psychological Barriers to Care Instrument. This instrument measures the dimensions of cultural/religious barriers and embarrassment barriers.

Evaluation of health care. The evaluation of health 
care is defined as the consumer's beliefs about the benefit of treatment and the quality of medical care provided (Cummings, et. al., 1980). This variable was operationalized using a modified Health Measures Scale developed by Reynolds, West, and Aiken (1990) to evaluate the perceived benefits of treatment and the client's satisfaction with the health care provider.

Threat of Illness. This variable refers to the individual's perception of symptoms and perceived susceptibility to the threat of cervical cancer. In this study, the threat of illness was operationalized using the susceptibility and seriousness subscales of the champion (1993) Health Belief Model Scale.

Knowledge about disease. Knowledge refers to the individual's cognitive awareness of the causes of cervical cancer and the availability of a reliable test for identifying early changes in cervical tissue. operationalization of the knowledge concept was through a questionnaire developed to determine factual knowledge about cervical cancer which was based on an adaptation of the Factual Knowledge Questionnaire developed by Stillman (1977) .

Social Network. The influence of one's social network on the decision to obtain preventive Pap screening was operationalized by an adaptation of the supportiveness subscale of the Interpersonal support of Health Habit Change 
scale developed by Zimmerman and connor (1989).

\section{Summary}

This chapter has highlighted the significance of cervical cancer as a major disease affecting women and the importance of cervical screening as a way to identify new cases of cervical cancer. The use of a composite health model integrating the variables from 14 separate health models developed by Cummings, Becker, \& Maile (1980) was used as a framework for exploration of the factors that effect consumers' health decisions. Discovery of the effect of the variables in the composite model on women's intent to participate in preventive cervical cancer screening provides clinicians with information that may be used to develop intervention strategies to increase utilization of Pap smears to detect cervical cancer. Improvement in Pap screening attendance results in reduced morbidity and mortality associated with cervical cancer and assists in attainment of the national health goals. 
CHAPTER II

REVIEW OF THE LITERATURE

This chapter provides a review of the literature relevant to the study variables. Iiterature that supports the relationship of the predictor variables to the outcome variable is explored.

\section{Barriers to Health care}

Access to health services is determined by an individual's ability to participate in the service. Restriction to access may occur on a system level or on a personal level. Examples of system level restrictions to care include many of the complex issues with which our nation currently struggles such as lack of coverage for all individuals, lack of providers, and managing costs of these services. In this study, this type of access to care was controlled by the setting. By utilizing members of a Health Maintenance organization (HMO) as the sample, the study focused on the other personal access issues that may prevent a consumer from utilizing preventive health services.

HMOs are a type of health care organization that provide varying aspects of health insurance and direct health care services to clients. The HMO was designed to control costs through pre-paid enrollment of members and through extensive education and screening programs that are 
expected to be an integral part of maintaining members' health. All HMO members are guaranteed access to services. Utilization of services is controlled by a primary care provider assigned to each member. Fee for utilization of services varies by the type of HMO but generally all services are included in the monthly subscription cost (Langwell, 1990). The early successes of HMO cost reduction have been attributed to a decrease in hospital utilization through case management. More recently, costs are being managed more aggressively by focusing on prevention, health screening, and education in order to maintain the health of HMO members. This approach is thought to save both inpatient and outpatient costs associated with illness (Mullen \& Zapka, 1981).

Accessibility to health care in this study focused on those subjective consumer barriers that limit participation in health care. When access to the system is not available, one can identify barriers that prevent this entry. Barriers, as defined by Webster (1990 p.115) are "anything that holds apart, separates, or hinders." Knowing how to access services, make appointments, or even knowing what type of health care provider to consult may prove to be a formidable task. The concept of barriers as costs inherent in health action was first described by Rosenstock (1966) as part of the Health Belief Model (HBM).

A variety of barriers are described in the literature. 
System barriers such as waiting time, travel time and travel distance to appointments were described by Finnerty, Mattie, and Finnerty (1973) and Wan and Yates (1975) as reasons for patients not following up with appointments and dropping out of treatment.

Financial costs have also been described as barriers to obtaining care. Lack of coverage by insurance, out of pocket expenses, and lost work time have all been identified as barriers (Gift, 1978; Harris, 1975). The elderly are extremely affected by costs of care and frequently do not seek out care due to financial restraints (Antzak \& Branch, 1985; Harris, 1975).

one significant barrier to participation in screening examinations is fear. Fear of finding a lump and embarrassment during the examination has accounted for women not performing a breast self-exam (Stillman, 1977; Trotta, 1980). Fear, anxiety, false modesty and shyness were determined to be significant factors in why women delayed medical treatment when breast lumps were found (Gold, 1964). Fear was identified as a significant barrier to receipt of care (Davidson \& Clements, 1971; Knopf, 1976; Peters, Bear, \& Thomas, 1989).

In an analysis of reasons given by Hispanic women for non-participation in cervical smear exams (Peters, Bear: \& Thomas, 1989), six categories of barriers were identified: cognitive barriers relating to lack of knowledge about the 
necessity for the exam; emotional barriers such as fear or embarrassment; dislike for the procedure; economic barriers relating to direct costs or costs associated with lost work time; logistics barriers such as lack of transportation or child care, and social barriers resulting from the lack of support of others including professionals, kin and non-kin. Cognitive, fear, and social barriers were found to be the most significant predictors of lack of participation in Pap screening.

In summary, much of the research on barriers to health care has focused on system barriers such as limited medical care due to the consumer's ability to pay or lack of health services being provided such as in an inner city area. Current efforts in redirecting health care toward providing more universal coverage may result in improvement of this type of access barrier. other barriers that are of a more internal nature continue to prevent consumers from utilizing services even when those services are available and low cost. Availability of low cost or free screening services and convenient availability, all hallmarks of an HMO system, have not been enough to increase utilization of some very basic screening services. No research was found that explores the effect of personal barriers on participation in preventive health screening in a managed care environment. 


\section{Evaluation of Health care}

Perceived benefits associated with a health action and the quality of medical care provided are the dimensions included in this variable from the composite model analysis. Several studies have found that participants in preventive or screening programs had a strong positive belief that their actions would preserve or improve their health (Battistella, 1971; Gabrielson, 1967; Kegeles, 1963).

Champion (1985) found a significant correlation between the perceived benefits of breast self-exam (BSE) and the frequency with which women performed the exam. In a study undertaken to explain the practice of breast self-exam in 301 women, the results indicated that women who perceived a positive benefit of early detection of breast cancer were more likely to perform the examination on a routine basis. similar findings were reported by Calnan and Moss (1984). Women who attended an educational program on BSE were interviewed a year later to determine the best predictors of continued BSE performance. Perceived benefits of BSE was found to be the variable that showed the most discrimination between women who continued to perform BSE and those that did not continue to perform BSE (standardized discriminant score .91, $\mathrm{Q}=<.05$ ).

Kegeles, Kiescht, and Haefner (1965), in a national survey of health behaviors related to cancer prevention, found that women who had Pap screenings were more likely to 
believe that early detection of cancer was beneficial to their health.

In a study of women's intention to participate in breast screening, Lauver (1992) studied the effect of utility, affect, and social norm. Utility was defined as the women's belief about the worth of care seeking in relation to the perceived benefits. The results of the study found a high correlation $(r=.33)$ between utility and intention to seek care. Rutledge (1987) also found a high correlation between the frequency of performance of breast self exam and women's perception of the benefits of routine examination. In a regression analysis including susceptibility, age, social support, and perceived benefits about treatment, perceived benefits was the only significant predictor variable accounting for $27 \%$ of the variance.

In a similar study, Reynolds, West, and Aiken (1990), studied the effect of participation in education programs on women's intent to use mammography. Women assigned to the education group demonstrated increased levels of knowledge and higher levels of perceived benefit of mammography than women assigned to the control group $(F=5.63, p=<.05)$. Lashley (1987) studied the predictors of breast selfexamination from the perspective of the Health Belief Model. In contrast to previous findings, this study did not support benefits as a significant predictor of BSE in this group of 101 elderly women. 
In summary, the perceived benefits of a health action have been shown to have an impact on the utilization of health services with few exceptions. Most of the recent literature has focused on the perceived benefits related to mammography or BSE. In contrast to mammography, which is a relatively new examination with less widespread knowledge than Pap examination, no recent studies have explored the relation of perceived benefits to utilization of Pap exams.

No studies have been conducted in a prepaid health care environment which has a major emphasis on the prevention of illness through education and routine preventive screening. Some evidence exists that HMO subscribers are better educated and may have chosen the HMO over other types of health delivery systems, yet, there is a lack of confirmatory research regarding HMo member beliefs about the benefit of health services.

\section{Threat of Illness}

In the composite model of health belief variables identified by cummings, et. al. (1980), the threat of illness variable is a synthesis of two other variables both originating from the Health Belief Model: susceptibility and seriousness.

Perceived susceptibility is the degree to which an individual perceives the subjective risk of contracting a condition (Rosenstock, 1966). A high level of perceived 
susceptibility to a health problem has been correlated with individuals seeking care for cancer (Kegeles, Kiescht \& Haefner, 1965), information on accident prevention (Becker \& Maiman, 1975), and information about dental disease (Kegeles, 1963). A study by Haefner and Kirsch (1970) described the effectiveness of educational programs in increasing awareness of susceptibility to health risks. This increased awareness was subsequently followed by a search for health care intervention to minimize effects of such risk.

A study conducted by Calnan (1984) to determine significant predictors for attendance and non-attendance at BSE classes, identified six significant variables: perceived vulnerability, marital status, personal health beliefs, control over health, use of preventive services, and social support. Perceived vulnerability was the variable that contributed most to the discriminant function analysis (Standardized Discriminant Score $.50, \mathrm{P}=<.001$ ).

Hallal (1982) found that a high belief in susceptibility to breast cancer was positively correlated with performing breast self-exam. Other studies have found no relationship or a negative relationship between perceived susceptibility to an illness and health actions (Champion, 1985; Howe, 1981; Stillman; 1977; Weisenberg, Kegeles \& Lund, 1980)

Perceived seriousness of a condition describes the 
degree to which the person feels there may be a negative impact either on physical well being or broader family or social relationships (Rosenstock, 1966). Early work done by Kegeles (1965) and Haefner and Kirsch (1970) determined that people generally consider cancer to be a serious illness that may lead to death. Citing this finding, some later researchers have indicated that an assumption underlying their research is that cancer is always perceived as serious. In these studies the component of seriousness was not operationalized (Gramase, 1982; Stein, Fox, Murata, \& Morisky, 1992). In a causal model study of mammography usage, the authors deleted the construct of seriousness determining that cancer is always perceived as serious (Stein, Fox, Murata, \& Morisky, 1992). Interestingly, while low levels of threat may not be sufficient to motivate an individual to action, extremely high levels of threat or overwhelming seriousness as perceived by the individual can lead to inaction (Leventhal, 1965). Jette, Brock, Phelps and Naessens (1981) determined that responses to general questions about severity and susceptibility differed from condition specific responses. As a result of the study, the authors suggested not mixing general and specific items when measuring the threat posed by an illness. In contrast to previous findings supporting seriousness and susceptibility as predictors of health screening behavior, Lashley (1987) found these predictors 
were not significant in a study of elderly women performing BSE.

In summary, the perceived threat of illness has been shown to effect participation in health care. Research has supported consumers' views that cancer is viewed as a serious and potentially life threatening disease. Many studies, however, have not operationalized the seriousness component, but rather determined that seriousness was assumed by the consumer. Threat of illness should be examined in conjunction with other variables that have been shown to affect health seeking behavior.

\section{Knowledge About Disease}

Knowledge about disease is an important factor that may influence health seeking behavior. There is frequently misunderstanding about the necessity of tests or procedures for screening purposes, especially when the a person is asymptomatic. In a study of 101 women to identify reasons for non-attendance at cervical screening clinics in England, Eardley, Elkind, Spencer, Hobbs, Pendleton, and Haran (1989), found the most significant reason reported for nonattendance was lack of knowledge about the preventive nature of the exam. Women in the study stated that they felt "well", and did not recognize that Pap tests identified abnormal cellular pathology rather than treated symptomatology. other reasons given by the women included 
the perceived lack of need for screening due to hysterectomy, menopause, or advanced age.

similar results were reported by Peters, Bear, and Thomas (1989) in a study of the barriers to cervical cancer screening among Hispanic women. Subjects indicated that they did not receive Pap smears because they weren't sick or they felt fine. This lack of knowledge of the rationale for the preventive nature of Pap screening was determined to be a cognitive barrier to care.

Studies conducted by the National Cancer Institute (1980) have shown that many at-risk individuals did not participate in screening or preventive care because they did not recognize the need. Beliefs about lack of symptoms or misunderstanding the likelihood of risk may result in avoidance or delay in seeking treatment (Gold, 1964 ; Trotta, 1980). The degree of control an individual feels in the situation has been shown to predict behavioral action they take. Conversely, increased knowledge about the need for screening for early cancer detection has resulted in women receiving recommended health screenings (Kegeles, 1963).

Studies exploring the relationship of knowledge to preventive health screening have consistently identified that lack of knowledge influences participation in health screening. Misinformation has been shown to account for the lack of participation in preventive health screening 
particularly among women receiving preventive cervical cancer smears. These studies provided direct support for further investigation of knowledge as a factor affecting participation in health activities.

Women members of HMOs have increased availability of educational programs due to the emphasis of the HMOs on education and preventive screening. No research has been conducted in the HMo setting to evaluate the impact of these educational opportunities on the rate of participation in cervical cancer screening.

\section{Social Network}

The original research on behavioral models of health focused predominately on the role of individuals in determining their own health behavior (Kegeles, 1963; Rosenstock, 1966). Subsequently, researchers identified that the influence of others, both family and non-family members of the larger social community, had a significant impact on an individual's health behavior (Andersen, 1968; Kar, 1977).

Spousal support and encouragement have been identified as significant in decreasing the dropout rate of participants in a post-coronary exercise program (Andrew, Oldridge, Parker, Cunningham, Rechnitzer, Jones, Buck, Kavanagh, \& Shephard, 1981). In a review of 728 participants in a post-coronary rehabilitation program, the 
three main reasons given by participants for not continuing the program were inconvenience, unfavorable perceptions of the exercise program, and family support factors. The influence of the spouse was found to be the most significant factor in determining if the participant would continue in the exercise program. Participants who perceived lack of support were three times as likely to drop out. In this study, the support of work colleagues or other family members was not as significant as spousal support in maintaining program attendance.

The impact of social influence can not be overlooked as a potential barrier to health care. The influence of family and friends has been demonstrated to effect utilization of immunizations (Glasser, 1958), engaging in positive health practices (Hubbard, Muhlenkamp, \& Brown, 1984), and undertaking a fitness program (Heinzelmann \& Bagley, 1970; Pender \& Pender, 1985).

The impact of significant others on the success of an individual engaged in changing health behavior has been demonstrated in a study by zimmerman and connor (1989). Eighty four persons participating in a work site health promotion program to improve their lifestyle were surveyed to determine the impact their family, friends, or coworkers had on their ability to incorporate the new lifestyle changes. Participants were interviewed to determine the level of support they expected from family, friends, and co- 
workers while they were trying to make a lifestyle change. The actual amount of support given by each group while the participant was trying to make a lifestyle change, and the degree of support they provided the participant to maintain changes they had made were also determined. In all categories, family members provided the most support and encouragement for health behavior changes. Overall, the amount of support given by family, friends, and coworkers significantly influenced the achievement of the health goals.

In an analysis of reasons given by Hispanic women for non-participation in cervical smear exams, Peters, Bear, and Thomas (1989) found that social barriers resulting from the lack of support of others, including professionals and kin and non-kin influence, was a significant predictor of lack of participation in Pap screening.

Lauver (1992) found that there was a significant positive relationship between the social norm and women's intent to participate in breast screening. Calnan and Moss (1984) found that women who received encouragement from friends and relatives were more likely to attend educational sessions on BSE. Similar results for breast screening were also found by Timko (1987) and Valois, Desharnais, and Godin (1988). Social influence was, however, not found to be a significant predictor of intent for African-American women (Lauver, 1992). 
In summary, these studies indicated that significant others may provide considerable influence in the decision to seek or accept preventive health care and support the individual in taking health action. The relationship of social support to participation in preventive cervical cancer screening for women members of an HMO has not been explored.

\section{Demographic Information}

Several demographic factors have been associated with higher levels of participation in Pap screening attendance. In an analysis of responses of 12,252 women who participated in the 1987 National Health Interview Study on cancer, Calle, Flanders, Thun, and Martin (1993) identified five significant demographic predictors of underuse of Pap smear screening. These factors were: age, race, income level, education, and marital status. Women of races other than white, black and Hispanic had the lowest compliance rate for screening with $34.9 \%$ of women not screened. Having never been married, being older than 65 years of age, and having an education of less than 12 years also were significant factors in not obtaining screening exams.

Similar findings were obtained from another study investigating predictors of mammography and Pap screening (Hayward, Shapiro, Freeman, \& Corey, 1988). This study identified six variables that influenced participation in 
Pap screening: age, health, insurance status, income, education, employment status, and ethnicity. Participation in screening for women in the older age range of 65 and over was only 59\%. Contrary to other studies, this study found that black women had a higher rate of screening than either white or Hispanic women.

Research conducted by Warnecke (1983) found that after menopause, regular physician visits declined yet cervical cancer rates remained steady. Many women believe that after menopause they are no longer at risk for cervical cancer (King, 1987). In a study of the changing health habits of American women Makuc, Fried, and Kleinman (1989) found that as age increased, women were less likely to have Pap screening done. Hayward, Shapiro, Freeman and Corey (1988) also reported similar findings of decreasing number of Pap smears with increasing age. Calnan and Moss (1984) reported two significant demographic predictors of attendance at BSE classes: education $\left(\mathrm{x}^{2}=23, \mathrm{p}=<.001\right)$ and marital status $\left(X^{2}=8.3, p=.05\right)$.

In summary, age, race, and education level have been the variables most frequently associated with participation in health screening behavior. Socioeconomic level has also been a significant factor, but in this study was controlled by the HMo setting. The relationship of the demographic variables of age, race, and education level on participation in preventive health screening in the HMO setting has not 
been addressed in the research.

\section{Summary}

Analysis of multiple models of health care has resulted in the identification of variables that are significant predictors of health care action. The key characteristics of these models have been proposed by Becker (1990) as a composite model ready for empirical testing. Each of the model variables, accessibility, evaluation, social network, knowledge, and threat of illness have been shown to influence health behavior.

Perceived barriers, both internal and external, prevent consumers from utilizing preventive health services even when cost and access are not an issue. Perceptions about the benefits of health screening and the degree of personal threat of illness identified by the consumer has been shown to have a direct impact on the utilization of services. Studies exploring the relationship of knowledge and health behavior have demonstrated that misinformation and lack of understanding are significant in explaining lack of participation.

The influence of family, friends, and significant others has been shown to have a direct relationship on the initiation and maintenance of health behavior changes. The demographic variables of age, race, and education level have been consistently identified as significant predictors of utilization of health screening, in particular Pap smear 
screening. Despite research support for the significance of these variables individually, no study has investigated the effect of these combined predictor variables in a single population related to a specific health action or addressed the ability of the predictor variables to explain a consumer's intention to take health action. In addition, no research has investigated the relationship of these variables in an HMO setting where health screening and health promotion are essential components of the HMo model. 


\section{CHAPTER III}

METHODOLOGY

This chapter details the design of the study as well as the methods used to implement it. Information about the sample, data collection methods, and the data analysis approach are presented.

\section{Research Design}

A multivariate, descriptive comparative design was used to study the effect of age, education level, race, general barriers to health care, psychological barriers to health care, evaluation of health care, threat of illness, knowledge, and social network on future intention to participate in Pap smear screening for cervical cancer between two groups of women. Since the predictor variables were not subject to manipulation by the researcher, an ex post facto design allowed for investigation of the naturally occurring variables. A descriptive comparative design was selected due to its ability to explain the effect of the predictor variables on the outcome variable and to describe differences in the variables for each of the two comparison groups of women.

Analysis of the literature revealed a strong link between the variables of this study and the composite model used as the conceptual framework for this study. Since no 
research testing this model was identified in the Iiterature, construction of a descriptive comparative design was determined to be the most suitable design given the early stages of investigation of these variables. Only those variables with support in the literature were included in the model (Munro, Visintainer, \& Page, 1986). A potential threat to the internal validity of this study was that the outcome measure of this study was the participant's intent to participate in Pap screening rather than the actual behavior of participating in a screening exam. An argument could be made that mere statement of intention does not necessarily translate into action. There is however, a strong association between intention to perform a behavior and actual behavior (Ajzen \& Fishbein, 1987). Potential uncontrolled threats to the study include the ex post facto design and the possibility that unexplained variance in this study may be the result of unidentified variables.

\section{Sample}

The target population for this study was specified as women members of an FMO. This was done to control for other extraneous variables that have been identified as barriers to care, specifically, access and having a primary care provider. The women selected for survey were between 18 and 70 years of age, able to read and respond to a written questionnaire, and willing to participate as indicated by 
completing the survey.

Utilizing the medical records database of a prepaid health plan in Southern California, women who had Pap screenings that fell into two screening groups were identified by the HMO staff. Group 1 represented those women who had no Pap exam in the past year, and Group 2 represented women who had a Pap exam in the previous year. From these groups, a stratified random sample of 325 members for each group of participants and non-participants were selected in order to assure an adequate number of responses.

A total of 96 women (30\%) comprised Group 1. For Group 1, women with no recent history of Pap examination, a power of .93 was obtained using a medium effect size and an alpha of .05 . For Group 2, 69 women (21\%), with a record of a recent Pap examination, a power of .78 was obtained using a medium effect size and an alpha of .05 (Cohen, 1988).

Caution must be used when low response rates occur with questionnaires since only a selected portion of the sample may have returned the questionnaire (Polit \& Hungler, 1991). In addition, selection bias may be a potential rival explanation for the study results (Krathwohl, 1985). selection bias may have occurred in this study because the researcher had no control over the health plan members who chose to return the surveys making it difficult to generalize the results to the population (Polit \& Hungler, 1991). Both of these potential threats were controlled 
through the use of a stratified random sample and the collection of demographic data. Consultation with the HMO data analysts allowed the researcher to compare the aggregated demographics of each group of respondents to the non-respondents in order to determine how well the respondents matched the characteristics of the total HMO membership population. Comparison of the two groups revealed essentially the same demographic characteristics in terms of age, education level, ethnicity, marital status, and length of membership in the health plan. Table 1 summarizes the demographic information for each of the two groups of women respondents.

As reflected in Table 1, group 1 respondents, who had no recent history of Pap examination, ranged in age from 21 to 65 with a mean age of 42.83 ( $S D=11.51$ ). Fifty one percent had achieved an AA degree or had attended some college, 28\% had completed high school, and an additional $18 \%$ of this group were college graduates or had completed graduate degrees. Race/ethnicity was reported as $80 \%$ white, 11\% Hispanic, 2\% Asian, 3\% Black, 1\% Native American, and 2\% were unreported. The average length of membership in the healthplan for this group of women was 3.8 years.

In Group 2, women who had evidence of a recent Pap examination, ages ranged from 22 to 64 with a mean age of $39.24(\mathrm{SD}=11.52)$. The majority (49\%) had achieved an $\mathrm{AA}$ 
Table 1

Demographic Profile of the Sample $(n=165)$

\begin{tabular}{|c|c|c|}
\hline & $\begin{array}{l}\text { Group } 1 \\
\text { With No } \\
\text { Pap } \\
(n=96)\end{array}$ & $\begin{array}{l}\text { Group } 2 \\
\text { With Pap } \\
(n=69)\end{array}$ \\
\hline Age Range & $21-65$ & $22-64$ \\
\hline \multicolumn{3}{|l|}{ Education Level } \\
\hline Less than 12 th Grade & $1 \%$ & $1 \%$ \\
\hline High School & $28 \%$ & $18 \%$ \\
\hline Some college or $A A$ & $51 \%$ & $49 \%$ \\
\hline College Graduate & $12 \%$ & $14 \%$ \\
\hline $\begin{array}{l}\text { Some Graduate School or Graduate } \\
\text { Degree }\end{array}$ & $6 \%$ & $11 \%$ \\
\hline Not Reported & $2 \%$ & $7 \%$ \\
\hline \multicolumn{3}{|l|}{ Race } \\
\hline White & $80 \%$ & $79 \%$ \\
\hline Hispanic & $11 \%$ & $8 \%$ \\
\hline Black & $3 \%$ & 1\% \\
\hline Asian & $2 \%$ & $4 \%$ \\
\hline Native American & $1 \%$ & $1 \%$ \\
\hline Not Reported & $3 \%$ & $7 \%$ \\
\hline \multicolumn{3}{|l|}{ Marital status } \\
\hline Married & $76 \%$ & $69 \%$ \\
\hline Never Married & $10 \%$ & $17 \%$ \\
\hline separated & $5 \%$ & $1 \%$ \\
\hline Divorced & $5 \%$ & $10 \%$ \\
\hline Widowed & $3 \%$ & $1 \frac{9}{6}$ \\
\hline Not Reported & $1 \%$ & $2 \%$ \\
\hline
\end{tabular}

Reproduced with permission of the copyright owner. Further reproduction prohibited without permission. 
degree or had attended some college, and $18 \%$ had completed high school. College graduates comprised $14 \%$ of the sample, 6\% had completed graduate degrees, and $1 \%$ reported less than a high school education. Race/ethnicity was reported as $79 \%$ white, $8 \%$ Hispanic, 4\% Asian, 1\% Black, 1\% Native American, and $4 \%$ were unreported. This group reported their average length of plan membership as 4.0 years.

\section{Instruments}

Eight instruments were used in this study: Melnyk (1990) General Barriers to Health Care; DeBaca (1993) Psychologic Barriers to Health Care; Health Measures Scale (Aiken, 1990); Seriousness and Susceptibility subscales of the Champion (1993) Health Belief Model Scale; Factual Knowledge Questionnaire (Stillman, 1977); Interpersonal Support of Health Habit Change (Zimmerman \& Connor, 1989); a demographic questionnaire, and a scale to measure the outcome variable. A summary table of the instruments is presented in Table 2 . Melnyk Barrier to care Instrument

The Melnyk (1990) General Barriers to Health Care Instrument (BCI) was used to measure the individuals' perceived barriers to obtaining a yearly Pap smear examination (see Appendix A). The Melnyk BCI was developed to operationalize the concept of barriers from the perspective of the Health Belief Model. The Melnyk BCI is a 
Table 2

Instrumentation Summary

\begin{tabular}{|c|c|c|c|c|c|}
\hline Concept & Measure & Reference & Validity & Reliability & $\begin{array}{l}\text { Current Study } \\
\text { Reliability }\end{array}$ \\
\hline \multirow[t]{2}{*}{ Accessibility } & $\begin{array}{l}\text { General Barriers to } \\
\text { Health Care Scale }\end{array}$ & Melnyk (1990) & Content, Construct & в. .95 & g. .92 \\
\hline & $\begin{array}{l}\text { Psychological Barriers } \\
\text { to Health Care Scale }\end{array}$ & DeBaca (1993) & Content, Construct & a .87 & a .87 \\
\hline Evaluation of Health Care & Benefits Scale & Reynolds, West, Aiken (1990) & Content, Construct & 8. .94 & a .88 \\
\hline \multirow[t]{2}{*}{ Threat of Illiness } & $\begin{array}{l}\text { Susceptibility } \\
\text { Subscale }\end{array}$ & Champion (1993) & $\begin{array}{l}\text { Content, Construct, } \\
\text { Criterion }\end{array}$ & a .90 & a .93 \\
\hline & Seriousness Subscale & Champion (1993) & $\begin{array}{l}\text { Content, Constnuct, } \\
\text { Criterion }\end{array}$ & g .80 & g. .80 \\
\hline Knowledge About Disease & $\begin{array}{l}\text { Stillman Factual } \\
\text { Knowledge } \\
\text { Questionnaire }\end{array}$ & Stillman (1977) & Content & Not Determined & a. 72 \\
\hline Social Network & $\begin{array}{l}\text { Adaptation of } \\
\text { Interpersonal support of } \\
\text { Health Habit Change } \\
\text { Scale }\end{array}$ & Zimmerman and Connor (1989) & Content & a .67 & a .85 \\
\hline
\end{tabular}

$\mathrm{a}=$ Cronbach Alpha coefficient 
27 item, four point, Likert-type rating scale with a response range of 1 (none) to 4 (greatly). Scoring consists of summing the responses to obtain a total score with the resulting data at the ordinal level of measurement. A higher score indicates that the consumer perceives more barriers. The pilot instrument was tested with 800 members of an HMO to determine their perceived barriers to preventive health care (Melnyk, 1990). Construct validity was established with exploratory factor analysis and resulted in the identification of five subscales: provider/consumer relationship, fear, cost, inconvenience, and site related factors. All five subscales were used in this study and a total scale score derived. Melnyk (1990) reported a cronbach alpha reliability coefficient of .95 for the entire scale. Standardized alpha results for each of the subscales was: provider/consumer relationship (.91), fear $(.76)$, cost $(.85)$, inconvenience $(.63)$, and siterelated factors $(.77)$. In the current study, reliability for the total Melnyk scale using the Cronbach's alpha coefficient was .92 . DeBaca Psychologic Barriers to Health Care The DeBaca (1993) Psychologic Barriers to care (DPBC) was a newly developed instrument designed to measure the internally perceived, psychological barriers to health care utilization (Appendix B). The instrument measures the dimensions of religion/culture and embarrassment as they may 
act as barriers to participation in preventive health care. The DPBC is a 15 item, Likert-type rating scale with a five point response range from 1 (strongly disagree) to 5 (strongly agree). Scoring consists of suming the responses and obtaining a total score. A high score indicates a higher level of perceived barriers. The total scale score of the DPBC was calculated separately from the score Melnyk Barriers to Care instrument. Data obtained from the DPBC was at the ordinal level of measurement. The content Validity Index for the DPBC was .86 .

Construct validity was determined through factor analysis and the construction of a multitrait-monomethod matrix. Factor analysis using principle component analysis with Varimax rotation and a factor loading criterion of .4 resulted in a two factor structure accounting for $54 \%$ of the variance (Nunnally, 1978). Factor loadings for the 6 item religion/culture subscale ranged from .48 to .86 , while factor loadings for the 9 item embarrassment subscale ranged from .48 to .90 .

A multitrait-monomethod matrix was developed to examine convergent and discriminant construct validity. Using a criterion of .40 to .70 (Anastasi, 1988), the DPBC instrument demonstrated convergence with the fear subscale of the Melnyk (1990) instrument $(x=.40)$. Divergent validity was demonstrated by low levels of correlation with the seriousness and susceptibility scales, -.14 and -.16 
respectively. The standardized alpha for the total 15 item instrument was .87 , while standardized alphas for the subscales were religion/culture .81 and embarrassment .87 (DeBaca, 1993). These values are above the minimum value of .70 suggested by Nunnally (1978) for a new instrument. In the current study the entire DeBaca Psychologic Barriers to Care instrument was used. A Cronbach's alpha of .87 was obtained for the total scale, .81 for the religion/culture subscale, and .87 for the embarrassment subscale. Health Measures scale

A Health Measures Scale (HMS) was developed by Reynolds, West, and Aiken (1990) as part of a study to determine the effectiveness of intervention strategies in increasing utilization of mammography screening (Appendix c). The scale consists of seven subscales that measure the constructs of the Health Belief Model including intention, susceptibility, severity, benefits, barriers, knowledge, and compliance. Responses are indicated on a 7 point Likerttype rating scale. The anchors for each of the subscales change to reflect the concept being measured. Scoring consists of summing the responses for each of the subscales and results in data measured at the ordinal level. Since each of the subscales measures a single component of the Health Belief Model, a total score for the scale is not calculated. Scores for each of the subscales are calculated by summing the responses for each subscale item. Content 
validity using expert judges was reported by the researchers in developing the scale items. Confirmatory factor analysis using a factor loading criterion of .40 yielded the seven subscales as theoretically identified. Reliability for each of the subscales was: intention .86; susceptibility .91; severity .83 ; benefits .94 ; barriers .65 ; knowledge .78 ; and compliance .88 .

The Health Measures scale was designed to predict women's utilization of mammography (Reynolds, West \& Aiken, 1990). One hundred fifty six women were randomly assigned to three groups (education, education and psychological support, and no support) in order to determine the effect of the intervention on intention to receive a mammogram. A simplified causal model with four variables was found to account for the most compliance with mammography. Significant $t$ values $(g<.05)$ were obtained for the following variables: benefits, susceptibility, severity, and barriers.

In the current study, the benefits subscale was used to measure the variable of evaluation of health care. Benefits scale items were scored on a six point likert-type rating scale with a scoring range of 1 (very little) to 6 (very much). Questions on the benefits subscale were adapted, with permission, to reflect participants' evaluation of cervical screening rather than mammography. The results of reliability testing in the current study 
revealed a standardized alpha of .88 .

Champion Health Belief Model scale

Champion's (1984) Health Belief Model Scale (HBMS)

which is based on the theoretical framework of the Health Belief Model, conceptualizes health behavior as an individual's attitudes toward susceptibility, seriousness, benefits, barriers, confidence, and health motivation (Appendix D). The 42 item scale measures each of these six subdimensions on a five point, Likert-type rating scale with a scoring range from 1 (strongly disagree) to 5 (strongly agree). Scores for each of the subscales are obtained by determining the mean score for the subscale. The total scale score is determined by adding the mean scores of each subscale. Data obtained from this scale is at the ordinal level.

Champion (1984) developed and tested the original instrument in a sample of 301 women using a dependent variable of breast self-exam. The scale has recently been revised and tested in a sample of 581 women regarding their attitudes about breast self-examination (Champion, 1993). Content validity was established using a panel of expert judges. Construct validity was established with exploratory factor analysis. Scale items loaded on the originally conceptualized subdimensions with all loadings achieving .45 or higher (Champion, 1993). In addition, criterion validity was tested using multiple regression to relate scale 
responses to actual performance of breast self-examination. Twenty-four percent of the variance in the practice of breast self-exam was predicted by the scale, and $F$ values for each of the subscales were significant at the $<.01$ level.

Reliability of the revised instrument was established using the internal consistency and test-retest methods. Test-retest reliability was conducted by correlating the results of the written survey with the results obtained by asking the same scale questions in a personal interview two to eight weeks later. Correlation of the results produced a test-retest reliability ranging from .45 to .70 .

In this study only the susceptibility and seriousness subscales of the Champion HBM scale were used. The Champion HBM Scale is one of the most frequently utilized instruments used to measure the concepts of the Health Belief Model. It was the only instrument found in the literature with substantial psychometric evaluation. The stability of this psychometric testing led to the decision to use the seriousness and susceptibility subscales to measure these variables in the study. Additional psychometric properties are reported for only these two subscales. Factor loadings, using a minimum criterion of .40 (Nunnally, 1978), for the 5 questions in the susceptibility subscale, ranged from .76 to .84 , and .47 to .62 for the 7 item seriousness subscale. Cronbach's alpha 
for the susceptibility subscale was .93 and .80 for seriousness. Since the Champion scale reflects behaviors related to breast self-examination, the researcher, with permission from the author, adapted the wording to appropriately reflect cervical cancer screening. Internal consistency reliability testing of these subscales in the current study revealed a Cronbach's alpha of .90 for the susceptibility subscale and .80 for the seriousness subscale.

\section{Factual Knowledge Questionnaire}

A five item questionnaire (Appendix E) was adapted from a Factual Knowledge Questionnaire (FKQ) developed by stillman (1977). The stillman questionnaire was designed to evaluate women's level of knowledge about risk factors for breast cancer. No reliability or validity results were reported by stillman.

For use in this study, the five question FKQ was designed to measure the level of cognitive knowledge about the effectiveness of cervical screening to detect cervical cancer. Cervical cancer questions were developed from literature produced by the American Cancer Society. The content validity for this questionnaire was developed using two oncology clinical nurse specialists to determine if the information included in the Factual knowledge Questionnaire was representative of the knowledge base one would expect consumers to have. The content validity index for the 
questionnaire was 1.00 (Waltz \& Bausell, 1986).

Responses to the factual knowledge questions are answered on a scale with 1 for true and 2 for false. The score for the scale was determined by the number of items correctly answered resulting in measurement at the interval level. Cronbach's alpha reliability for the Factual Knowledge Questionnaire in this study was .72 . Interpersonal support of Health Habit change

The influence of significant others on the decision to seek preventive health care was measured with an adaptation of the Zimmerman and Connor (1989) Interpersonal support of Health Habit Change Scale (ISHHC). The Interpersonal Support of Health Habit Change Scale (Appendix F) was developed to measure the degree of perceived support a person received from family, friends, or co-workers as they undertook a change in health habits such as exercise. The scale consists of four subscales assessing the degree of support the person felt from each of their significant others in four ways: anticipated support prior to change, support during the behavior change, how others changed their habits to support the individual, and support for maintaining the behavior change. Responses are scored on a Likert-type rating scale producing data at the ordinal level of measurement. The scoring range for the scale is 1 (no support) to 5 (excellent support). A summed score was used for data analysis with higher scores indicating higher 
levels of perceived support. Content validity for the scale was established using expert judges. No CVI was determined. Cronbach alpha reliability was reported at .67 .

Research has indicated that responses to general health questions may differ markedly from answers to specific health intention questions (Jette, Brock, Phelps and Naessens, Cummings, Brock, Phelps, \& Naessens 1981). With the permission of the authors, this scale, which asks about general support for health habit change, was adapted to reflect the screening behavior of interest in this study cervical smears for cancer. Reliability testing in the current study showed a Cronbach's alpha of .85 . Demographic ouestionnaire

A demographic questionnaire (Appendix G), designed by the researcher, was used to obtain information on three of the study variables: age, race, and education level. other personal information was gathered to describe the sample. An additional question was included to obtain the subjects' self-report of their last Pap smear. This question was designed to determine if the examination was done by another health care provider. Care provided outside of the HMO would not be reflected in the individual's database, and this question was intended to avoid erroneously reporting that the subject had not received the screening exam, when, in fact they had received such an exam. Data obtained from the age and education level questions were considered to be 
categorical data, while data received from the race question was nominal.

Intent to Participate in Pap screening

The dependent variable for this study was the women's intention to participate in Pap screening within the next year. This variable was included with the demographic information and measured by a three level ordinal response scale $(1=$ very likely; 2 = somewhat likely; and $3=$ not at all likely).

one potential threat to the internal validity of this study is translation fidelity. Translation fidelity, as described by Krathwohl (1985), concerns the method in which the study variables are operationalized. In order to control for this threat, all instruments used in this study, except the Factual Knowledge Questionnaire and the measure of intent to participate in Pap screening, had known psychometric properties. Instrumentation or history may also be a rival explanation since the surveys were completed at the member's home and there was no control by the researcher.

\section{Data collection Procedures}

Approvai for the research study was obtained through the University of San Diego's Committee on the Protection of Human Subjects (Appendix H). A letter of agreement from the participating HMO was also obtained. Anonymity of the HMO 
members was maintained through the following mechanisms. Staff members of the participating HMO identified, from their database, women who had received a Pap smear in the previous year, and women who had not received a Pap smear in the previous year. The researcher did not have access to member information in the HMO database and was not able to identify any individual HMO member. Study questionnaires were prepared and mailed by the HMO staff to preserve subject anonymity.

All subjects received a data collection packet which included a cover letter, the demographic questionnaire, and the research instruments. These documents had different graphic designs for each of the two groups. This enabled the researcher to compare the subject's self-report of Pap attendance with the database record of Pap screening. Women who had no recent documentation of Pap screening were coded as Group 1 and women with documentation of recent examination were coded as Group 2. A stamped self-addressed envelope was included to facilitate return of the questionnaires to the HMO office.

\section{Data Analysis Plan}

Demographic information was analyzed with descriptive statistics including frequencies, mean, and standard deviation. Bivariate correlations using the Pearson Product Moment Correlation Coefficient $(r)$ were conducted between 
the predictor variables to test for multicollinearity. Bivariate correlations to test for interrelations between the predictor variables and the outcome variable were also calculated.

Research questions one and two were examined with multiple regression to assess the effect of the predictor variables on women's intent to participate in Pap screening in each of the two groups. Data met the assumptions of multiple regression including: normal distribution and equal variability (homoscedasiticy); a linear relationship between the predictor and outcome variable; and the assumption that the sample was representative of the population (Munro, Visintainer, \& Page; Verran \& Ferketich, 1987). The predictor variable of race was considered to be at a nominal level of measurement and was assigned a dummy code in order to include it in the regression analysis (Cohen, 1983; Munro, Visintainer, \& Page, 1986). For each of the groups, the nine predictor variables were entered into the regression model, stepwise, in order to determine the amount of variance explained by each of the predictor variables on the criterion variable. All of the study variables were included in the regression analysis since the purpose of the regression study was explanatory. Stepwise regression was chosen because it provided a more accurate picture of the predictive power of each variable in the model (Waltz \& Bausell, 1986). Regression results were examined for beta 
weights, amount of explained variance, and significance level.

In order to answer research question three, data for the two groups of women were analyzed with a t-test to determine if differences existed between the scores of the study variables for each of the two groups of women. The $t$-test is commonly used to compare differences between two groups (Hinkle, wiersma, \& Jurs, 1988; Munro, Visintainer, \& Page, 1986). In this study, data used for the variables were considered to be at the ordinal level of measurement rather than at the interval level required to meet $t$-test assumptions. Some controversy exists over the strict interpretation of ordinal and interval levels of measurement. Utilization of ordinal level data in statistical tests such as ANOVA, t-tests, or multiple regression does not significantly alter the results and is considered a pragmatic application of measurement theory in many disciplines (Brink \& Wood, 1989; Burns \& Grove, 1987; Waltz, Strickland, \& Lenz, 1991). other assumptions for the $t$-test were met through random selection of groups that were mutually exclusive and had normal distribution of the dependent variable. Unequal group variances, as determined by the $F$ test, were treated by using the separate variance formula when calculating the t-test results (Hinkle, Wiersma, \& Jurs, 1988; Munro, Visintainer, \& Page, 1986). SPSSPC software was used to 
perform all statistical analyses.

\section{Summary}

A descriptive comparative research design was used to determine the effect of age, education level, race, general barriers to health care, psychological barriers to health care, evaluation of health care, threat of illness, knowledge, and social network on the predictor variable of future intent to participate in Pap smear screening for cervical cancer. A stratified random sample of two groups of women were selected from the membership of an HMO. Group 1 women $(n=96)$, had a recent history of Pap examination while Group $2(n=69)$ had no recent history of examination. Eight instruments were used to measure the study variables. A stepwise multiple regression analysis was done to predict the effect of the predictor variables on women's intent to participate in preventive cervical cancer screening for each of the two groups. The t-test was used to evaluate significant differences between the two groups of women. 
CHAPTER IV

RESULTS

The focus of this research was to examine the ability of age, education level, race, general barriers to health care, psychological barriers to health care, evaluation of health care, threat of illness, knowledge, and social network to predict women's future intentions to participate in preventive health screening for cervical cancer. The results of this study in terms of data management and findings for the research questions are presented in this chapter.

\section{Data Reduction}

Prior to performing data analysis to answer the research questions, returned surveys were inspected to determine the completeness of the subject responses. only one returned questionnaire was discarded because the responses were not complete enough to be used in data analysis. Other instruments were missing minimal amounts of information such as one or two answers. Comparison of the outputs of the multiple regression analysis with and without mean substitution revealed that only $6 \%$ of the cases were missing data. Considering such a small number of missing data, a decision was made to treat the missing data by using mean substitution for the value during data analysis 
(Tabachnik \& Fidell, 1983).

Data collected on race was treated as nominal data. Prior to analysis, dumy coding of this variable was performed in order to be able to include this variable in the analysis. Two vectors were used to code the responses, $0=$ non-white and 1 = white (Munro, Visintainer, \& Page, 1986) •

Scores for each of the scales were determined as previously described in Chapter III, and bivariate correlations between each of the study scales were examined for multicollinearity. Correlations between the scales were computed using Pearson Product Moment Correlation coefficients. None of the bivariate relationships approached the .60 to .80 level indicative of multicollinearity (Munro, Visintainer, \& Page, 1986). The bivariate correlational matrix for each of the study scales is shown in Table 3 .

\section{Research Questions}

Bivariate correlations between the predictor variables and the outcome variables were examined to determined the strength and direction of the relationship and are reported for each of the study groups. Results of the regression analysis for questions one and two were interpreted using the beta weights and their significance level, the amount of explained variance $\left(R^{2}\right)$, and the adjusted $R^{2}$. The adjusted $R^{2}$ was used because it accounts for the number of variables 
Table 3

Bivariate correlations for study scales

\begin{tabular}{|c|c|c|c|c|c|c|}
\hline Scale & $\mathrm{BCI}$ & DPBC & HMS & HBMS & FKQ & ISHHC \\
\hline $\mathrm{BCI}$ & & $.27 \star$ & .03 & .15 & -.02 & -.10 \\
\hline DPBC & & & $-.36 * *$ & -.05 & -.02 & -.12 \\
\hline HMS & & & & .11 & .01 & $.40 * *$ \\
\hline HBMS & & & & & .08 & -.02 \\
\hline FKQ & & & & & & .01 \\
\hline ISHHC & & & & & & \\
\hline
\end{tabular}

Key:

BCI $=$ Melnyk Barriers to Care Instrument

DPBC = DeBaca Psychological Barriers to Care Scale

HMS $\quad=$ Health Measures Scale

HBMS $\quad=$ Champion Seriousness/Susceptibility subscales

FKO = Factual Knowledge Questionnaire

ISHHC = Interpersonal support of Health Habits Change

$* \quad \mathrm{Q}<.01$

** $\quad \mathfrak{Q}<.001$ 
in the equation and adjusts for sample size (Munro,

Visintainer, \& Page, 1986). For all statistical procedures. a .05 level of probability was used for statistical significance. Findings for research questions one and two are presented in Table 4.

Research Question one: What is the effect of age, education level, race, general barriers to health care, psychological barriers, evaluation of health care, threat of illness, knowledge, and social network on the future intentions to participate in preventive health screening for cervical cancer for women whe have not recently participated in preventive cervical cancer screening? Correlations between the predictor variables of age, education level, race, general barriers to health care, psychological barriers to health care, evaluation of health care, threat of illness, knowledge, and social network and the criterion variable of intent to participate in Pap smear screening for women with no recent Pap examination revealed that the variables of evaluation of health care $(x=-.37, p=<.001)$, race $(x=$ $.25,2=<.001)$ and psychological barriers to care $(\Sigma=$ $.22, \&=<.05$ ) were significant.

Results of the multiple regression analysis for the sample of women who had not recently had a Pap exam showed two significant variables: evaluation of health care $(B=-$ $.04, \mathfrak{Q}=<.001)$ and race/ethnicity $(B=.13, \mathfrak{Q}=<.04)$. The amount of variance accounted for by these two variables was 
Table 4

Multiple Regression Results Between the Predictor Variables and Women's Intent to Participate in PAP ( $n=165)$

\begin{tabular}{|c|c|c|c|c|c|c|}
\hline Group & Variable & $r$ & $\begin{array}{l}\text { Beta } \\
\text { Weight }\end{array}$ & $\underset{\mathrm{R}}{\text { Unique }}$ & $\underset{R^{2}}{\text { Cumulative }}$ & $E^{*}$ \\
\hline \multicolumn{7}{|c|}{$\begin{array}{l}\text { Women with } \\
\text { no recent } \\
\text { Pap }(N=96)\end{array}$} \\
\hline & $\begin{array}{l}\text { Evaluation of } \\
\text { Health Care }\end{array}$ & $-0.37 *$ & -0.04 & 0.13 & 0.13 & 14.12 * \\
\hline & Race & $0.25 *$ & 0.13 & 0.04 & 0.17 & $9.48 * *$ \\
\hline & Melnyk Barriers & 0.00 & -0.00 & 0.00 & & NS \\
\hline & DeBaca Barriers & $0.22 * \star$ & 0.17 & 0.01 & & NS \\
\hline & $\begin{array}{l}\text { Threat of } \\
\text { IIIness }\end{array}$ & -0.02 & 0.00 & 0.00 & & NS \\
\hline & Knowledge & 0.07 & 5.30 & 0.00 & & NS \\
\hline & Social Network & 0.00 & 0.00 & 0.00 & & NS \\
\hline & Age & -0.01 & 0.00 & 0.00 & & NS \\
\hline & Education Level & -0.07 & -0.02 & 0.00 & & NS \\
\hline \multicolumn{7}{|c|}{$\begin{array}{l}\text { Women with } \\
\text { recent Pap } \\
(\mathrm{N}=69)\end{array}$} \\
\hline & $\begin{array}{l}\text { Evaluation of } \\
\text { Health Care }\end{array}$ & $-0.46 * \star$ & -0.04 & 0.22 & 0.22 & $19.23 *$ \\
\hline & DeBaca Barriers & $0.37 \star \star$ & 0.02 & 0.07 & 0.29 & 13.21 * \\
\hline & Melnyk barriers & 0.09 & 0.00 & 0.00 & & NS \\
\hline & $\begin{array}{l}\text { Threat of } \\
\text { IIIness }\end{array}$ & -0.08 & -0.01 & 0.04 & & NS \\
\hline & Knowledge & 0.02 & 0.08 & 0.01 & & NS \\
\hline & Social Network & -0.19 & -2.71 & 0.00 & & NS \\
\hline & Age & 0.08 & 0.00 & 0.01 & & NS \\
\hline & Education Level & -0.03 & -0.00 & 0.00 & & NS \\
\hline & Race & 0.06 & 0.03 & 0.00 & & NS \\
\hline
\end{tabular}

$\star=\mathrm{p}<.001$

$\star \star=0<.05$

NS $=$ Not Significant

Reproduced with permission of the copyright owner. Further reproduction prohibited without permission. 
$17 \%$.

Research ouestion Two: What is the effect of age, education level, race, general barriers to health care, psychological barriers, evaluation of health care, threat of illness, knowledge, and social network on the future intention to participate in preventive health screening for cervical cancer for women who have recently participated in preventive cervical cancer screening? Correlations between the predictor variables of age, education level, race, general barriers to health care, psychological barriers to health care, evaluation of health care, threat of illness, knowledge, and social network and the criterion variable of intent to participate in Pap smear screening revealed that both evaluation of health care $(x=-.46, g=<.05)$ and psychological barriers to health care $(r=.37, g=<.05)$ had a significant correlation with intent to obtain a Pap exam.

In the group of women who had recently had a Pap exam, multiple regression analysis identified two variables that were significant in explaining $29 \%$ of the variance: evaluation of health care $(B=-.04, \mathcal{Q}=<.001)$ and psychological barriers ( $\mathrm{B}=.02, Q=<.001$ ).

In summary, the results of the regression analysis for research questions one and two, revealed that the evaluation of health care variable was a significant predictor of 
women's intention to participate in preventive cervical cancer screenings in both groups of women. In the group of women with no recent Pap history, race was also a significant predictor of intention. For the group of women with recent Pap screening, evaluation of health care and psychological barriers also explained intention. Residual Analysis

Residual analysis for each of the two groups of women was conducted to test the variables not included in the model and to determine if the test assumptions were met (Verran \& Ferketich, 1987). The normality of the data was verified using a histogram. A scatterplot of the standardized residuals revealed a linear and normal distribution of the independent and dependent variables. In order to determine constant variance the expected values of the residuals were plotted against the actual values. The resulting pattern demonstrated no relationship.

Research Question Three: Are there significant differences in future intent to participate in cervical cancer screening between women whe have not recentiy participated in preventive cervical cancer screening and women who have recently participated in cervical cancer screening? A ttest was periormed to determine if there were differences in the variables between the two groups of women. The two groups were randomly selected and mutually exclusive, the 
dependent variable was normally distributed, and the unequal variance was treated by using the separate variance formula (Munro, Visintainer, \& Page, 1986).

T-test scores comparing the Group 1 and Group 2 women for each of the study variables indicated that there were no significant differences between the two groups of women. T-test analysis of the comparisons between Groups 1 and 2 are presented in Table 5 .

\section{Summary}

This chapter has presented the results of the analysis of the survey data. Multiple regression analysis for research questions 1 and 2 revealed significant differences in the variables that influence intent to participate in preventive Pap screening in each of the two groups of women. For women with a recent history of Pap examination, the predictor variable of evaluation of health care and psychological barriers accounted for $29 \%$ of the variance in intent to receive a Pap smear in the next year. In the group of women with no recent history of Pap examination, evaluation of health care and race accounted for $17 \%$ of the variance in intent. When $t$-test analysis was performed, no significant differences were found between the two groups of women. 
Table 5

Comparison of Twe Groups of Women in Relation to study Variables

\begin{tabular}{|c|c|c|c|c|c|}
\hline Variable & $\begin{array}{l}\text { Group } 1 \\
\text { (No Pap) } \\
\text { (n=96) } \\
M /(S D)\end{array}$ & $\begin{array}{l}\text { Group } 2 \\
\text { (Pap) } \\
(\mathrm{n}=69) \\
M /(\mathrm{SD})\end{array}$ & df & $t$ & $\mathbf{p}$ \\
\hline Age & $\begin{array}{c}42.83 \\
(11.51)\end{array}$ & $\begin{array}{c}39.24 \\
(11.52)\end{array}$ & 140 & 1.95 & .053 \\
\hline $\begin{array}{l}\text { Education } \\
\text { Level }\end{array}$ & $\begin{array}{l}2.94 \\
(.84)\end{array}$ & $\begin{array}{l}3.16 \\
(.93)\end{array}$ & 124 & -1.47 & .15 \\
\hline Race & $\begin{array}{l}2.21 \\
(.71)\end{array}$ & $\begin{array}{l}2.29 \\
(.85)\end{array}$ & 143 & -.17 & .87 \\
\hline $\begin{array}{l}\text { General } \\
\text { Barriers to } \\
\text { Health Care }\end{array}$ & $\begin{array}{c}43.74 \\
(18.54)\end{array}$ & $\begin{array}{c}45.91 \\
(20.15)\end{array}$ & 117 & -1.30 & .20 \\
\hline $\begin{array}{l}\text { Psychological } \\
\text { Barriers to } \\
\text { Health Care }\end{array}$ & $\begin{array}{l}27.58 \\
(10.40)\end{array}$ & $\begin{array}{l}26.73 \\
(8.80)\end{array}$ & 149 & -.02 & .99 \\
\hline $\begin{array}{l}\text { Evaluation of } \\
\text { Health care }\end{array}$ & $\begin{array}{l}25.39 \\
(4.63)\end{array}$ & $\begin{array}{l}23.79 \\
(6.15)\end{array}$ & 114 & 1.18 & .24 \\
\hline $\begin{array}{l}\text { Threat of } \\
\text { Illness }\end{array}$ & $\begin{array}{l}27.61 \\
(9.30)\end{array}$ & $\begin{array}{c}29.46 \\
(10.41)\end{array}$ & 119 & -1.12 & .26 \\
\hline Knowledge & $\begin{array}{l}3.46 \\
(.88)\end{array}$ & $\begin{array}{l}3.36 \\
(.77)\end{array}$ & 153 & .63 & .53 \\
\hline Social Network & $\begin{array}{l}19.56 \\
(6.98)\end{array}$ & $\begin{array}{l}17.47 \\
(7.43)\end{array}$ & 87 & .61 & .55 \\
\hline
\end{tabular}

Reproduced with permission of the copyright owner. Further reproduction prohibited without permission. 


\section{CHAPTER V}

\section{SUMMARY, DISCUSSION AND RECOMMENDATIONS}

This chapter presents a summary of the research findings, identifies the strengths and limitations of the study, and discusses the implications of the research findings within the scope of nursing research, practice, administration, and education.

The focus of this research study was to explore the factors affecting women's decisions to participate in preventive cervical cancer screening using a composite model of the theoretical and empirical work of 14 health theorists. The conceptual model was proposed by Cummings, Becker, \& Maile (1980) as a means to integrate competing yet similar aspects of theories describing factors affecting consumer's health behaviors. By achieving agreement among the theorists, Becker hoped to advance health behavior research beyond a debate of semantics and into empirical testing of the model. Although the composite model was proposed in 1980, no reports of testing the model were found in the literature.

The purpose of this descriptive-comparative study was to investigate the effect of the predictor variables of the model adapted as the study framework (barriers, evaluation of health care, threat of illness, knowledge, social network, age, education level, and race) on the outcome variable of women's intent to participate in cervical cancer screening 
examinations. This study also addressed the differences in the predictor variables between two groups of women: those that have had a recent Pap examination and those that do not have a recent history of Pap examination. The differences in the predictor variables for the two groups are summarized below.

These research questions were answered with data obtained from two groups of female members of a southern California Health Maintenance Organization (HMO). Group 1 consisted of 96 women who had no documentation of a Pap screening examination in the previous year. Group 2 was comprised of 69 women who had documentation of Pap screening within the last year. Using multiple regression techniques, the study supported some but not all predictor variables as significant in determining women's intent to participate in cervical cancer screening. Sample With No Recent Pap History

For Group 1, evaluation of health care and race were the significant predictors of intention to receive an examination with a total of $17 \%$ explained variance. The evaluation of health care predictor variable accounted for $13 \%$ of the variance for those women without recent screening. Race was also a significant predictor accounting for an additional $4 \%$ of the variance. Sample with Recent Pap Examination For Group 2, two variables were significant in 
explaining $29 \%$ of the variance in intent to receive a Pap examination: evaluation of health care and psychological barriers. Evaluation of health care emerged as the strongest predictor (22\% of variance) of women's intention to participate in Pap screening. Psychological barriers added an additional $7 \%$ of explained variance.

In the multiple regression analysis, the evaluation of health care variable emerged as the variable explaining the greatest amount of variance for both groups. Evaluation of health care was identified as the consumer's perceived benefits about the treatment as well as their perception of the quality of care provided. Consumer's expectations about the effectiveness of treatment, in this case, the effectiveness of the Pap smear to detect cervical cancer, is significantly related to their intention to seek preventive screening. However, the significant $r$ of -.37 indicated that as member perception of the benefits of Pap examination went up, the member intent to participate in examination decreased. This inverse relationship does not support other findings in the literature. Prior studies have found that intent to participate or actual participation in health screening is positively related to perceived benefits. In studies of women's intention to perform breast self-examination, Rutledge (1987) reported that perceived benefit of treatment was significant and accounted for $27 \%$ of the variance and stein, Fox, Murata, \& Morisky (1992), reported that benefits 
accounted for $12 \%$ of the variance. In a study of cervical cancer screening barriers, Peters, Bear, and Thomas (1989) reported that women who did not fully understand the reason for screening were less likely to receive an exam than women who aware of the purposes of screening.

Another significant predictor variable in the multipie regression analysis was psychological barriers $(x=.22)$. In this study, access was defined as barriers that may prevent a consumer from accessing health services. The concept of barriers preventing access to care has been identified in a number of studies as being significant to consumer's participation in health care. In a review of 17 studies on the Health Belief Model, the barrier concept was significant in predicting preventive health utilization behavior in $100 \%$ of the studies (Janz, \& Becker, 1984). Champion (1953) identified that barriers significantly influence women's participation in breast self-examination. When barriers were high, participation in screening was low. The findings of the current study are similar to the results obtained by wheeler and Rundall (1980), who found that barriers strongly influence use of services $(x=.27)$. The absence of barriers to care, such as having a regular physician, leads to an increase in the use of health services. This study identified that perceived psychological barriers are influential in determining women's participation in cervical screening examinations. Due to the intimate nature of the Pap 
examination, concerns of fear and embarrassment have a direct impact on women's intention to utilize this preventive services.

Several demographic variables were identified in the literature as significantly related to health screening and, in particular, participation in Pap screening. Most frequently age, race, and education level have been positively associated with higher levels of screening. In this study, only the variable of race proved to be a significant predictor and only within the group of women not recently having a screening examination. A significant relationship between race and intent is consistent with other findings in the literature. Previous studies have found that whites have a higher level of participation in screening than Hispanics (Harlan, Bernstein, \& Kessler, 1991; Hayward, Shapiro, Freeman, \& Corey, 1988). Historically, much of the difference in participation has been linked to the lower socioeconomic status of black women (Peters, Bear, \& Thomas, 1989) and lack of access to the health care system (Wheeler \& Rundall, 1980), but in groups where these factors are controlled for, screening rates of black women are surpassing that of whites (Harlan, Bernstein, \& Kessler, 1991). Pap screening is lowest among Hispanic women, women of other races, and older Black women (Calle, Flanders, Thun, \& Martin, 1993). This study did not support age anü eüiciaiion level as 
significant in determining intent. One explanation for this finding may be that the sample consisted of women in a limited age range with a high education level. Studies have shown that the extreme age populations, very young and very old, differ significantly in their screening rate (Peters, Bear, \& Thomas, 1989). Although the age ranges of the membership of the healthplan surveyed included these extreme age groups and diverse ethnic populations, the majority of respondents were not from these groups. Generally, a well educated, white female population is more likely to utilize preventive health services (Wheeler \& Rundall, 1980).

Although knowledge was proposed to be one of the significant factors influencing participation in health screening, scores in this study did not reach significance. Analysis of the knowledge scores of the two groups of women revealed that although there were not significant differences between the two groups of women in the knowledge score, scores in general were low. Iimitations in the psychometric properties of the Factual knowledge Questionnaire may have contributed to the non-significant findings of the knowledge variable in this study. Confusion seemed to exist in the group of respondents about the recommended interval for Pap screening. Calculation of the frequencies of correct responses to the factual knowledge questions revealed that 94.5\% of the women surveyed believed that the Pap screening examination should be done on a yearly basis. However, only 
35\% of the women were aware of the American Cancer Society recommendation that screening frequency may be decreased following three or more normal examinations.

Perception of threat of an illness and the seriousness of that illness comprised the variable of threat. Threat did not emerge as a significant predictor of intent to receive screening. Wheeler and Rundall (1980) identified that the perception of the threat of illness is greater in the aged and in those less educated. Since the study sample consisted of a well educated, middle aged population, the concept of threat may not have been identified.

Social support was not a significant variable in determining women's intention to participate in screening in this study. Reexamination of previous studies supporting this variable revealed that the focus of previous studies was on the maintenance of lifestyle changes as opposed to the focus of the current study on a sporadic screening procedure. Continuation of diet regimes and exercise programs may tend to impact the individual and their family to a greater extent than Pap screening. In a study by Wheeler and Rundall (1980), the availability of a primary care provider was the most important determinant of receiving preventive care. Analysis of the data related to social support indicated that the sample identified that their physicians were supportive the examination $89 \%$ of the time and that nurses were supportive $69 \%$ of the time. Given the nature of the HMO, the 
availability of a primary provider may have eliminated the need for the women to seek other sources of non-medical support such as that from family and friends.

The amount of explained variance in this study was low but comparable to the results obtained in studies using similar variables. Several reasons may account for the low amount of explained variance in this study. The ability to capture the subject's perception of the predictor variables may have been limited by the instrumentation. Health and health behavior have been shown to encompass complex ideology regarding perception of health and health risk. In the literature review relating to health behavior variables, no studies, other than those repeated by the same researcher, utilized the same scales or measures. This lack of repeated testing of instrumentation leaves few instruments with documented psychometric properties that have had extensive testing. This limitation may have affected the ability to adequately measure the variables.

A unique feature of this study was the utilization of the composite model of factors affecting health services utilization. Despite the inclusiveness of the model, not all variables influencing health behavior may have been captured by the model. Recent work by health theorists have identified self-efficacy and locus of control as influential in explaining health behavior. Self-efficacy has been defined as a person's confidence that they can perform a behavior 
necessary for accomplishing a change (Bandura, 1986). In addition, the concept of locus of control may have some explanatory power in describing an individual's belief that their actions may influence an outcome such as a health action (Rosenstock, Strecher, \& Becker, 1988; Strecher, DeVellis, Becker, \& Rosenstock, 1986).

Research studying the effect of the predictor variables used in this study has not been conducted in the HMO setting. Differences in the findings and the level of explained variance may be due to the unique characteristics of the HMO population. Further exploration may identify other variables that influence health behavior for members of prepaid health plans.

\section{Implications and Recommendations}

The results of this study can be utilized by nurses to improve the quality of care provided to clients. Recommendations are made in the areas of nursing research, practice, administration, and education.

\section{Nursing Research}

The variable accounting for the most significance in each of the two groups of women was evaluation of health care. Previous research had established that perceived benefits about treatment had a positive correlation with participation 
in health care. Since the effect of the evaluation of health care variable in this study was contrary to that which was expected, additional investigation with different methods may provide more information on the relationship of this variable to health behavior. Qualitative methodology may be used to identify additional underlying explanatory factors that would explain the inverse relationship of evaluation of health care to intent to participate in Pap screening. Utilization of a qualitative methodology may also be beneficial in identifying additional variables that were not considered in the conceptual model. Additional or different variables may be present in a managed care environment that have not been previously identified research conducted in other settings. Development of a longitudinal study to explore the outcome of the inverse relation of the evaluation of health care variable on intent to obtain a Pap smear may also help to explain this unexpected finding. Such a study may also result in identifying that the results obtained in the current study were spurious.

Due to the limited availability of instruments with extensive psychometric testing, validation and refinement of the research instruments to measure the variables is also recommended. Development and testing of instruments to enhance their level of precision, accuracy, and sensitivity will allow for more control in measurement of the variables affecting health behavior and may result in an increase in the 
amount of explained variance.

since this study demonstrated significant differences between groups of women, further research is necessary to see if similar findings would remain constant for other groups of women who do and do not participate in Pap screening. Replication with a larger sample comprised of a more ethnically diverse population would add to the findings of this study if similar results could be demonstrated. Additionally, new studies could replicate this study with other secondary health screening behaviors such as participation in cholesterol screening, mammography, or influenza vaccination.

Although the focus of this study was women, a similar lack of research on the health promotion habits of men also exists. Replication of this study with a male population may identify different factors that predict men's health behavior related to participation in health screening.

Two extensions of this project would provide additional information on health seeking behaviors. Since the outcome variable for this study was identified as intention to receive a Pap exam, a follow-up study could be made to determine the number of women who actually followed through and had the examination performed. Based on the significance of the evaluation of health care variable, an intervention study could be designed to measure the impact of a Pap screening education program on intent to participate in Pap screening. 
Nursing Practice and Administration

Since women's perceptions about the benefit of treatment was the most significant variable, there are opportunities for nurses in all clinical settings to impact health screening decisions. Assessment of the client's knowledge base regarding screening examinations is an important component of the professional nursing role. Obtaining a comprehensive health history, identification of high risk clients, and providing client education about the availability, benefits, and resources for health screening play an important role in the client's decision making process. Several studies have demonstrated that "provider cue" or the suggestion or recommendation of a health professional to receive an examination was highly correlated to participation (Wheeler \& Rundall, 1980). As the results of this study confirm, suggestion by the nurse or physician is more influential than encouragement offered by spouses, friends, or children to obtain Pap exams.

Nurses can assist clients to avoid "missed opportunities" for exams by assessing knowledge, providing appropriate information, and taking proactive steps to perform the exam if appropriate or scheduling the procedure on behalf of the client. After Pap screening, nurses play a vital role in clarifying the next steps for follow-up care, providing emotional support, and providing information about resources and referrals. 
Nursing administrators can support increased utilization of screening examinations by focusing on reducing or eliminating system barriers that may affect access or utilization of services. Improvement in notification of screening availability, extended hours, expansion of female providers, and providers that are familiar with language and cultural barriers all can serve to increase participation. Nursing Education

Schools of Nursing must continue to promote health screening and focus on the importance of teaching and counseling clients at every opportunity. Education of students should continue to focus on assessment of client's knowledge and communication of health promotion as a routine part of the curriculum. Incorporation of the latest information on health screening needs and updating according to national standards is imperative. It is clear from this study that consumers are confused regarding changes in recommended Pap screening. Health professionals who do not remain current will be giving inaccurate information.

Summary

This descriptive comparative study explored the relationship of general barriers to care, psychological barriers to care, evaluation of health care, threat of illness, knowledge, social network, age, education level, and 
race. There has been much investigation of reasons why individuals participate in health care but many studies have taken less than comprehensive approach by not using a comprehensive model. This study, based on the comprehensive framework of 14 health theorists, provides an initial attempt to isolate factors that are significant in determining how women make health screening decisions, particularly for Pap examinations. In summary, the study revealed that the factors related to women's intention to receive cervical screening examinations varied for each of the two study groups.

In the current cost constrained health care environment, it is important to expend resources wisely. Results of research identifying factors that affect utilization of preventive health services can benefit HMOs by generally improving the health of members and limiting the costs associated with illness and disability. Employers would also benefit from improved health of employees through reduction of health care costs, decreased absenteeism, and increased productivity. The results of this study provide a beginning step in identifying the variables most significant to health promotion behavior and enable health care professionals to focus limited resources where the most benefit will be achieved. 


\section{REFERENCES}




\section{REFERENCES}

Aday, L. (1975). Economic and non economic barriers to the use of needed medical services. Medical Care, 13, 447-456. Ajzen, I. \& Fishbein, M. (1980). Understanding attitudes and predicting social behavior. Englewood Cliffs, N.J.: Prentice-Hall.

American Cancer Society (1992). Cancer Facts and Figures 1992. New York: The Society. Anastasi, A. (1988). Psychological Testing, (6th ed.). New York: Macmillan.

Andersen, R. (1968). A behavioral model of families' use of health services. Center for Health Administration Studies, University of Chicago. Andrew, G., Oldridge, N, Parker, J., Cunningham, D., Rechnitzer, P., Jones, N., Buck, C., Kavanagh, T., \& Shephard, R. (1981). Reasons for dropout from exercise programs in post-coronary patients. Medicine and science in Sports and Exercise, 13, 164-168.

Antonovsky, A., \& Kats, R. (1970). The model dental patient: An empirical study of preventive health behavior. American Journal of Public Health, 57, 48 . Antzak, A. \& Branch, L. (1985). Perceived barriers to the use of dental services by the elderly. Gerodontics, 1, 194198. 
Bandura, A. (1986). Social foundations of thought and action. Englewood Cliffs, NJ: Prentice Hall. Battistella, R. (1971). Factors associated with delay in the initiation of physicians' care among late adulthood persons. American Journal of Public Health, 61, 1348. Becker, M. \& Maiman, B. (1975). Sociobehavior determinants of compliance with health and medical care recommendations. Medical care, 13, 10-24.

Becker, M. (1990). Theoretical models of adherence and strategies for improving adherence. In Shumaker, S., Schron, E., \& Ockene, J. (eds.). The Handbook of Health Behavior change, New York: Springer Publishing Company. Bice, T., Eichorn, R., \& Fox, P. (1972). Socioeconomic status and use of physician services: A reconsideration. Medical Care, 10, 261-271.

Blesch, K., \& Prohaska, T. (1991). Cervical cancer screening in older women. Cancer Nursing, 14, 141-147. Brink, P., \& Wood, M. (1989). Advanced design in nursing research. New York: Sage Publications. Burns, N., \& Grove, S. (1987). The practice of nursing research: conduct, critigue, and utilization. Philadelphia: W.B. Saunders. Calle, E., Flanders, W., Thun, M., Martin, M. (1993). Demographic predictors of mammography and Pap smear screening in US women. American Journal of Public Health, 83, 53-60. 
Calnan, M. \& Moss, S. (1984). The health belief model and compliance with education given at a class in breast self-examination. Journal of Health and Social Behavior, 25, $198-210$.

Champion, V. (1984). Instrument development for health belief model constructs. Advances in Nursing science, 6, 73-85. Champion, V. (1985). Use of the Health Belief Model in determining the frequency of breast self-exam. Research in Nursing and Health, 8, 373-379.

Champion, V. (1993). Instrument refinement for breast cancer screening behaviors. Nursing Besearch, 42, 139-143. Christopherson, W., Lundin, F., Mendez, W., \& Parker, J. (1976). Cervical cancer control: A study of morbidity and mortality trends over a twenty-one year period. Cancer, 38, 1357-1366.

Cohen, J. (1988). Statistical power analysis for the behavioral sciences (2nd ed.). New Jersey: Lawrence Erlbaum Associates, Publishers.

Cummings K., Becker, M., \& Maile, M. (1980). Bringing the models together: An empirical approach to combining variables used to explain health actions. Journal of Behavioral Medicine, 3, 123-145.

Davidson, R. \& Clements, J. (1971). Why don't they attend for a cytotest? A pilot study among a high-risk population. Medical officer, 1, 329-331. 
DeBaca, V. (1993). Psychological Barriers to Health Care: Development of a Measure. Unpublished manuscript. Dutton, D. (1978). Explaining the low use of health services by the poor: Costs, attitudes, or the delivery system? American Sociological Review, 43, 348-368. Eardley, A., Elkind, A., Spencer, B., Hobbs, P., Pendleton, L., \& Haran, D. (1985). Attendance for cervical screening - Whose problem? Social Science Medicine, 20, 955-962.

Fabrega, H. (1973). Toward a model of illness behavior. Medical care, 11, 470-484. Finnerty, F., Mattie, E., \& Finnerty, F. (1973). Hypertension in the inner city: An analysis of clinic dropouts. Sirculation, 47, 73-78.

Gabrielson, I. (1967). Factors affecting school health follow-up. American Journal of Public Health, 57, 48. Gift, H. (1978). Social and psychological barriers to dental care. Journal of the American college of Dentistry, 45, 170-183.

Gillam, S.J. (1991). Understanding the uptake of cervical cancer screening: The contribution of the health belief model. British Journal of General Practice, 41, 510-513. Glasser, M. (1958). A study of the public acceptance of the Salk vaccine. American Public Health, 48, 141-146. Gold, M. (1964). Causes of patient's delay in diseases of the breast. Cancer, 17, 564-577. 
Gramse, C. (1982). The relationship of internal-external health expectancies, value of health, health beliefs, and health behavior regarding breast self-examination in women. (Doctoral Dissertation, New York University, 1982). Dissertation Abstracts International, 43, 385388.

Green, L. (1975), Diffusion and adoption of innovations related to cardiovascular risk behavior in the public. In Enelow, A. and Henderson, J. (eds), Applying Behavioral Science to Cardiovascular Risk-Proceedings of a conference, American Heart Association, Washington, D.C.

Hallal, J. (1982). The relationship of health beliefs, health locus of control, and self-concept to the practice of breast self-examination in adult women. Nursing Research, 31, 137-142.

Haefner, D. \& Kirsch, J. (1970). Motivational and behavioral effects of modifying health beliefs. Public Health Reports. 85, 478.

Harlan, L., Bernstein, A., Kessler, L. (1991). Cervical cancer screening: Who is not screened and why? American Journal of Public Health, 81, 885-890.

Harris, R. (1975) . Breaking the barriers to better health care delivery for the aged. Gerontologist, 15, 52-56. 
Hayward, R., Shapiro, M., Freeman, H., \& Corey, C. (1988). Who gets screened for cervical and breast cancer? Results from a national survey. Archives of Internal Medicine, 148, 1177-1181.

Heinzelmann, F. \& Bagley, R. (1970). Response to physical activity programs and their effect on health behavior. Public Health Reports, 85, 905.

Hinkle, D., Wiersma, W., \& Jurs, S. (1988). Applied statistics for the behavioral sciences. Boston: Houghton Mifflin Company.

Holchbaum, G. (1958). Public participation in medical screening programs: A socio-psychological study, U.S. Government Printing office, Washington, D.C.

Howe, H. (1981). Social factors associated with breast selfexamination among high risk women. American Journal of Public Health, 71, 251-255.

Hubbard, P., Muhlenkamp, A., \& Brown, N. (1984). The relationship between social support and self-care practices. Nursing Research, 33, 266-269.

International Agency for Research on Cancer Working Group on Evaluation of Cervical Screening Programs (1986). Screening for squamous cervical cancer: Duration of low risk after negative results of cervical cytology and its implications for screening policies. British Medical Journal, 293: 695-664. 
Janz, N. \& Becker, M. (1984). The health belief model. Health Education ouarterly, 11, 1-47.

Jette, A., Cummings, M., Brock, B., Phelps, M., \& Naessens, J. (1981). The structure and reliability of health belief indices. Health Services Research, 16, 81-97.

Kar, s. (1977). Community interventions in health and family planning programs - A conceptual framework. International Journal of Health Education, 20, Number 1.

Kasl, S., \& Cobb, S. (1966). Health behavior, illness behavior, and sick role behavior. Archives of Environmental Health, 12, 246-266.

Kegeles, S., Kiescht, J., and Haefner, D. (1965). Survey of beliefs about cancer detection and taking Papanicolaou tests. Public Health Reports, 80, 815-823.

Kegeles, S. (1963). A field experiment attempt to change beliefs and behavior of women in an urban ghetto. Journal of Health and Social Behavior, 10, 115.

King, J. (1987). Women's attitudes toward cervical cancer. Update, 34, 160-168.

Knopf, A. (1976). Changes in women's opinions about cancer. Social Science Medicine, 10, 191-195. Kosa, J. \& Robertson, L. (1975). The social aspects of health and illness. In Kosa, J. \& Zola, I. (eds.), Poverty and Health: A Sociological Analysis, Harvard University Press, Cambridge. 
Krathwohl, D.R. (1985). Social and behavioral science. San Francisco: Jossey-Bass.

Langlie, J. (1977). Social networks, health beliefs, and preventive health behavior. Journal of Health and Social Behavior, 18, 244-260.

Langwell, K. (1990), Managed care and the Medicare program: Background and Evidence. Washington, D.C.: The Congress of the United States: Congressional Budget office, 1-16 Lashley, Marey E. (1987) . Predictors of breast selfexamination practice among elderly women. Advances in Nursing Science, 2, 25-34.

Leventhal, H. (1965). Fear communications in the acceptance of preventive health practices. Bulletin of the Academy of Medicine, 41, 1144.

Lundin, F., Christopherson, W., Mendez, W., \& Parker, J. (1963). Morbidity from cervical cancer: Effect of cervical cytology and socioeconomic status. Journal of the National Cancer Institute, 35, 1015-1025.

Lauver, D. (1992). Psychosocial variables, race, and intention to seek care for breast cancer symptoms. Nursing Research, 41, 236-241.

Makuc, D., Fried, V., \& Kleinman, J. (1989). National trends in the use of preventive health care by women. American Journal of Public Health, 79, 21-26.

Mechanic, D. (1968). Medical Sociology: A Selective View, The Free Press, New York. 
Melnyk, K. (1990). Barriers to care: operationalizing the variable. Nursing Research, 39, 108-112.

Mullen, P.D. \& Zapka, J.G. (1981). Health education and promotion in HMOs: The recent evidence. Health Education Quarterly, 8, 292-315.

Munro, B., Visintainer, M., \& Page, E. (1986). Statistical methods for health care research. J.B. Lippincott: New York.

National Cancer Institute (1980). Breast Cancer: A measure of Qrogress in public understanding. NIH Publication \#81-2291. Washington, D.C: US Government Printing office.

National Cancer Institute (1986). Cancer control objectives for the nation: 1885-2000. National center Institute Monographs. Bethesda, MD: U.S. Department of Health and Human Services. Pub No. 86-2880.

Nunnally, J. (1978). Rsychometric theory. McGraw-Hill: New York. Pender, N., \& Pender, A. (1985). Attitudes, subjective norms and intentions to engage in health behaviors. Nursing Research, 35, 15-18.

Peters, R., Bear, M., Thomas, D. (1989). Barriers to screening for cancer of the cervix. Preventive Medicine, 18, $133-146$.

Polit, D. \& Hungler, B. (1991). Nursing Research, Philadelphia: J.B. Lippincott. 
Reynolds, K., West. S. \& Aiken, L. (1990). Increasing the use of mammography: A pilot program. Health Education Quarterly, 17, 429-441. Rosenstock, I. (1966). Why people use health services. Milbank Memorial Fund Quarterly. 44, 94-127. Rosenstock, I., Strecher, V., \& Becker, M. (1988). Social learning theory and the health belief model. Health education quarterly, 15, 175-183. Rutledge, D. (1987). Factors related to women's practice of breast self-examination. Nursing Research, 36, 117-121. Stein, J., Fox, S., Murata, P., \& Morisky, D. (1992). Mammography usage and the health belief model. Health Education Quarterly, 19, 447-462. Stillman, M. (1977). Women's health beliefs about breast cancer and breast self-examination. Nursing Research, 26, 121-127.

Strecher, V., DeVellis, B., Becker, M., \& Rosenstock, I. (1986). The role of self efficacy in achieving health behavior change. Health education guarterly, 13, 73-92. Tabachnik, B. \& Fidell, I. (1983). Using multivariate statistics. San Francisco: Harper and Row. Timko, c. (1987). Seeking medical care for a breast cancer symptom: Determinants of intentions to engage in prompt or delay behavior. Health Psychology, 6, 305-328. 
Trotta, P. (1980). Breast self-exam factors influencing compliance. Nursing Research, 67, 219-224.

United States Department of Health and Human Services (1987). National Health Care Expenditures study: A summary of expenditures and sources of payment for personal health services from the national medical expenditure survey. Washington D.C.: U.S. Government Printing office.

United States Department of Health and Human Services (1990). Healthy People 2000: National Health Promotion and Disease Prevention statistics. Washington, D.C.: U.S. Government Printing office. Pub. No. 91-50212. Valois, P., Desharnais, R., \& Godin, G. (1988). A comparison of the Fishbein and Azjen and Triandis attitudinal models for the prediction of exercise intention and behavior. Journal of Behavioral Medicine, 11, 459-472.

Verran, J. \& Ferketich, S. (1987). Testing linear model assumptions: Residual analysis. Nursing Research, 36, $127-130$.

Waltz, C., \& Bausell, R. (1986). Nursing research:Design, statistics, and computer analysis. Philadelphia: F. A. Davis.

Waltz C., Strickland, 0., \& Lenz, E. (1991). Measurement in Nursing Research. F.A. Davis: Philadelphia. 
Wan, T., \& Yates, A. (1975). Prediction of dental services utilization: A multivariate approach. Inquiry, 12, 143156.

Warnecke, R., Havlicek, P., and Mansfredi, C. (1983).

Awareness and use of screening by older-aged persons. In Perspectives on Prevention and Treatment of cancer in the Elderly. By R. Yancik, et al. New York: Raven Press. Webster's New World Dictionary (1990). New York: PrenticeHall.

Weisenberg, M., Kegeles, S., \& Lund, A. (1980). Children's health beliefs and acceptance of a dental preventive activity. Journal of Health and Social Behavier, 21, 5974 .

Wheeler, J., \& Rundall, T. (1980) . Secondary preventive health behavior. Health Education Quarterly, Z, 243-262. Zimmerman, R. \& Connor, C. (1989). Health promotion in context: The effects of significant others on health behavior change. Health Education Quarterly, 16, 57-75. 
APPENDICES 
APPENDIX A

SAMPLE QUESTIONS

MELNYK BARRIERS TO CARE INSTRUMENT

\section{9}




\section{MELNYK BARRIERS TO CARE INSTRUMENT}

The relationships people have with their provider (primary doctor, gynecologist, or nurse practitioner) can affect whether or not they get the preventive care they need, such as getting a Pap smear. Please indicate how much you think each of the following characteristics of your relationship with your provider affects getting a Pap smear.

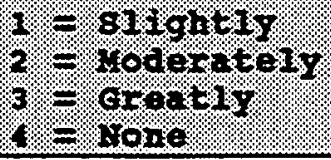

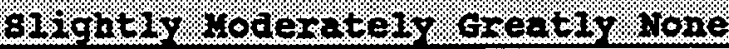

\begin{tabular}{llllll}
1 & $\begin{array}{l}\text { The provider may not } \\
\text { think my problems are } \\
\text { real or important. }\end{array}$ & 1 & 2 & 3 & 4 \\
\hline $6 \quad \begin{array}{l}\text { The provider doesn't } \\
\text { take enough time to } \\
\text { explain what they are } \\
\text { doing or why or to } \\
\text { answer questions. }\end{array}$ & 1 & 2 & 3 & 4 \\
\end{tabular}

Certain characteristics of the health care system can affect whether or not people get the preventive care they need, such as getting a Pap smear. Please indicate how much you think each of the following characteristics of the health care system affects your getting a Pap smear. Please circle the number of your answer.

\begin{tabular}{|c|c|c|c|c|c|}
\hline 11 & $\begin{array}{l}\text { The wait is too long at } \\
\text { the time of the } \\
\text { appointment. }\end{array}$ & 1 & 2 & 3 & 4 \\
\hline 12 & $\begin{array}{l}\text { The cost of } \\
\text { transportation and/or } \\
\text { parking is too high. }\end{array}$ & 1 & 2 & 3 & 4 \\
\hline 17 & $\begin{array}{l}\text { There is no } \\
\text { transportation to the } \\
\text { office or clinic. }\end{array}$ & 1 & 2 & 3 & 4 \\
\hline
\end{tabular}


People's past experiences or personal preferences and needs can affect whether or not they get the preventive care they need, such as having a Pap smear. Please indicate how much you think each of the following circumstances affects your getting a Pap smear. Circle the number you select as the answer.

\begin{tabular}{llllll}
19 & $\begin{array}{l}\text { No one can take care of } \\
\text { me like the provider I } \\
\text { used to have. }\end{array}$ & 2 & 3 & 4 \\
\hline 20 & $\begin{array}{l}\text { I don't like to be } \\
\text { examined or asked a lot } \\
\text { of questions. }\end{array}$ & 1 & 2 & 3 & 4 \\
\hline 21 & $\begin{array}{l}\text { Appointments to have a } \\
\text { Pap smear have to be } \\
\text { scheduled too far } \\
\text { ahead. }\end{array}$ & 1 & 2 & 3 & 4 \\
\hline
\end{tabular}


APPENDIX B

SAMPLE QUESTIONS

DEBACA PSYCHOLOGICAL BARRIERS TO CARE

92

Reproduced with permission of the copyright owner. Further reproduction prohibited without permission. 
DEBACA PSYCHOLOGICAL BARRIERS TO CARE

This questionnaire contains a series of statements about things that may hinder or prevent you from obtaining preventive health care examinations. For each statement circle the answer that most indicates how you feel about the statement. There are no right or wrong answers.

\begin{tabular}{|c|c|c|c|c|c|c|}
\hline \multirow[b]{2}{*}{2} & \multirow[b]{2}{*}{$\begin{array}{l}\text { In my culture it is a } \\
\text { sign of weakness to } \\
\text { take preventive } \\
\text { measures. }\end{array}$} & \multicolumn{2}{|c|}{ 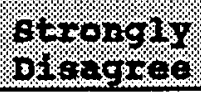 } & \multirow[b]{2}{*}{3} & \multicolumn{2}{|c|}{ 8terongh } \\
\hline & & 1 & 2 & & 4 & 5 \\
\hline 4 & $\begin{array}{l}\text { In my culture we } \\
\text { believe in alternative } \\
\text { therapies and I would } \\
\text { not have the exam. }\end{array}$ & 1 & 2 & 3 & 4 & 5 \\
\hline 5 & $\begin{array}{l}\text { Prayer is more } \\
\text { important in preventing } \\
\text { illness or disease than } \\
\text { receiving care from } \\
\text { health providers. }\end{array}$ & 1 & 2 & 3 & 4 & 5 \\
\hline 6 & $\begin{array}{l}\text { Illness is a deserved } \\
\text { punishment and there is } \\
\text { nothing I can do about } \\
\text { it. }\end{array}$ & 1 & 2 & 3 & 4 & 5 \\
\hline 9 & $\begin{array}{l}\text { It is embarrassing for } \\
\text { a provider of the } \\
\text { opposite sex to do the } \\
\text { exam. }\end{array}$ & 1 & 2 & 3 & 4 & 5 \\
\hline 12 & $\begin{array}{l}\text { I would prefer to have } \\
\text { a provider of the same } \\
\text { sex do the exam. }\end{array}$ & 1 & 2 & 3 & 4 & 5 \\
\hline
\end{tabular}




\section{APPENDIX C \\ SAMPLE QUESTIONS \\ BENEFITS SUBSCALE OF THE HEALTH MEASURES SCALE}


BENEFITS SUBSCALE OF THE HEALTH MEASURES SCALE

\begin{tabular}{|c|c|c|c|c|c|c|c|}
\hline & & 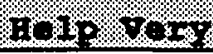 & 8 & 10 & A. 13? & 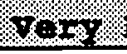 & $2020 \mathrm{ch}$ \\
\hline \multirow[t]{2}{*}{1} & $\begin{array}{l}\text { To what extent do you } \\
\text { believe that regular } \\
\text { cervical Pap smears will } \\
\text { help you stay healthy? }\end{array}$ & 1 & 2 & 3 & 4 & 5 & 6 \\
\hline & & \multicolumn{2}{|c|}{ 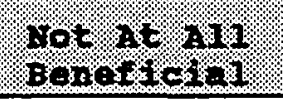 } & & \multicolumn{2}{|c|}{ 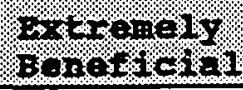 } & \\
\hline \multirow[t]{2}{*}{2} & $\begin{array}{l}\text { How beneficial do you } \\
\text { believe regular Pap } \\
\text { screening would be for } \\
\text { you? }\end{array}$ & 1 & 2 & 3 & 4 & 5 & 6 \\
\hline & $\begin{array}{l}\text { gragra } \\
\text { Yory }\end{array}$ & 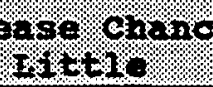 & 6eg. & $\begin{array}{l}\text { gacre } \\
\text { port? }\end{array}$ & (n) & ehrance & \\
\hline 3 & $\begin{array}{l}\text { To what extent do you } \\
\text { believe that regular Pap } \\
\text { smear exams will increase } \\
\text { your chance of cure if } \\
\text { cancer is detected? }\end{array}$ & e & 2 & 3 & 4 & 5 & 6 \\
\hline
\end{tabular}

Reproduced with permission of the copyright owner. Further reproduction prohibited without permission. 


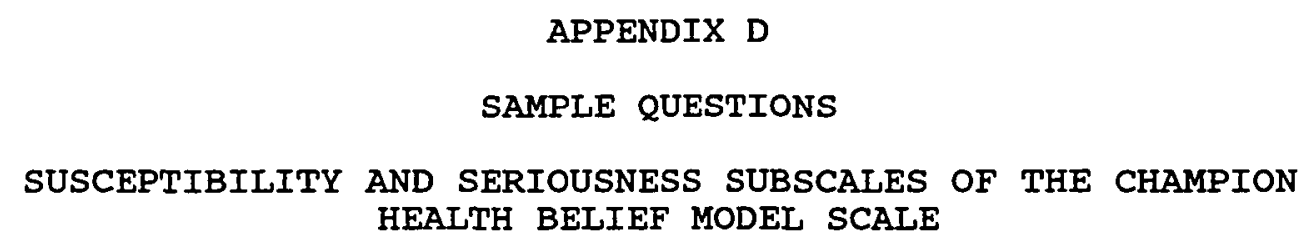

96

Reproduced with permission of the copyright owner. Further reproduction prohibited without permission. 


\section{SUSCEPTIBILITY AND SERIOUSNESS SUBSCALES OF THE CHAMPION HEALTH BELIEF MODEL SCALE}

We are interested in your beliefs about your susceptibility to cervical cancer and the effect that cervical cancer would have on your life. Please indicate the answer that is the closest to your belief.

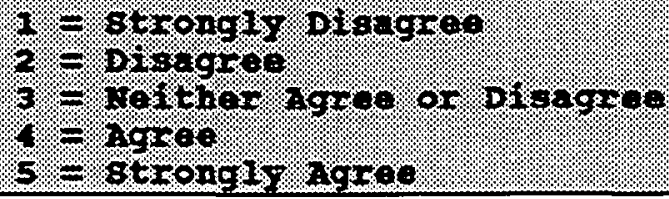

\begin{tabular}{|c|c|c|c|c|c|c|}
\hline \multirow[b]{2}{*}{1} & \multirow[b]{2}{*}{$\begin{array}{l}\text { My chances of getting cancer } \\
\text { of the cervix are great. }\end{array}$} & \multicolumn{2}{|c|}{ DIsagree } & \multirow[b]{2}{*}{3} & \multicolumn{2}{|c|}{ agreo } \\
\hline & & 1 & 2 & & 4 & 5 \\
\hline 5 & $\begin{array}{l}\text { I am more likely than the } \\
\text { average woman to get cancer } \\
\text { of the cervix. }\end{array}$ & 1 & 2 & 3 & 4 & 5 \\
\hline 7 & $\begin{array}{l}\text { The thought of cancer of the } \\
\text { cervix scares me. }\end{array}$ & 1 & 2 & 3 & 4 & 5 \\
\hline 10 & $\begin{array}{l}\text { If I develop cancer of the } \\
\text { cervix, I would not live } \\
\text { longer than } 5 \text { years. }\end{array}$ & & & & & \\
\hline 12 & $\begin{array}{l}\text { Problems I would experience } \\
\text { from cancer of the cervix } \\
\text { would last a long time. }\end{array}$ & 1 & 2 & 3 & 4 & 5 \\
\hline
\end{tabular}


APPENDIX E

SAMPLE QUESTIONS

FACTUAL KNOWLEDGE QUESTIONNAIRE 
FACTUAL KNOWLEDGE QUESTIONNAIRE

The following questions are designed to assess your knowledge of cervical cancer. Please answer the following questions based on your own knowledge.

\begin{tabular}{|c|c|c|c|}
\hline \multicolumn{3}{|c|}{$\mathrm{Imas}$} & \multirow{2}{*}{$\frac{20180}{2}$} \\
\hline 1 & $\begin{array}{l}\text { The Pap smear is a test to detect } \\
\text { early stages of cancer. }\end{array}$ & 1 & \\
\hline 4 & $\begin{array}{l}\text { All women } 18 \text { years and older or who } \\
\text { are sexually active should have an } \\
\text { annual Pap smear. }\end{array}$ & 1 & 2 \\
\hline 5 & $\begin{array}{l}\text { After a woman has had three or more } \\
\text { normal annual Pap smears, the exam } \\
\text { may be done less often as her doctor } \\
\text { advises. }\end{array}$ & 1 & 2 \\
\hline
\end{tabular}




\section{APPENDIX F \\ SAMPLE QUESTIONS}

INTERPERSONAL SUPPORT OF HEALTH HABIT CHANGE SCALE 
INTERPERSONAL SUPPORT OF HEALTH HABIT CHANGE SCALE

For each of the following individuals circle the number that indicates the amount of support and encouragement you receive from them to receive a routine Pap exam.

\begin{tabular}{|c|c|c|c|c|c|c|}
\hline & & 17028 & Poos & Four & 9000 & Bsorellent \\
\hline 1 & spouse/significant other & 1 & 2 & & 3 & 5 \\
\hline 5 & physician & 1 & 2 & & 3 & 5 \\
\hline
\end{tabular}


APPENDIX G

SAMPLE QUESTIONS

DEMOGRAPHIC QUESTIONNAIRE 
To assist in the analysis of this information, please answer the following questions about yourself. All of your answers will remain confidential and will in no way affect your treatment at the medical facility.

1. Age:

2. Marital status:

1. married

2. separated

3. divorced

4. widowed

5. never married

3. What is the highest level of education you have completed?

1. less than 12th grade

2. high school

3. some college, or $A A$ degree

4. college graduate

5. some graduate school or graduate degree

4. Race

1. black

2. white

3. Hispanic

4. American Indian or Native American

5. Asian or Pacific Islander

6. Other please specify

5. What is your religious preference?

1. Jewish

2. Catholic

3. Protestant

4. Mormon

5. Other

6. How long have you been a member of CIGNA? years months

7. Please indicate which response best describes your participation in a Pap exam for cervical cancer.

1. Examined during the past twelve months

2. Examined between the last 1 to 3 years

3. Examined between the last 4 to 5 years

4. Examined greater than five years ago

5. Never been examined 
8. If you have had a Pap exam, was it done at a cigna facility?

1. Yes

2. No

3. Unsure

9. If your Pap smear was not done at a Cigna facility, where was it done?

10. Please indicate how likely it is you will receive a Pap exam in the next year.

1. Very likely

2. Somewhat likely

3. Not at all likely

11. Who usually performs your Pap smear examination?

1. Primary doctor

2. Gynecologist

3. Nurse Practitioner

4. Other 